\title{
ASPECTOS BIOECOLÓGICOS E POTENCIAL DE PARASITISMO DE Encarsia formosa (GAHAN) (HYMENOPTERA: APHELINIDAE) SOBRE Bemisia tabaci BIÓTIPO B(GENNADIUS) (HEMIPTERA: ALEYRODIDAE) EM COUVE TOMATE E SOJA
}

\author{
KARINA MANAMI TAKAHASHI
}

Tese apresentada à Escola Superior de Agricultura "Luiz de Queiroz", Universidade de São Paulo, para obtenção do título de Doutor em Ciências, Área de Concentração: Entomologia.

P I R A C I C A B A

Estado de São Paulo - Brasil

Fevereiro - 2005 


\title{
ASPECTOS BIOECOLÓgICOS E POTENCIAL DE PARASITISMO DE Encarsia formosa (GAHAN) (HYMENOPTERA: APHELINIDAE) SOBRE Bemisia tabaci BIÓTIPO B (GENNADIUS) (HEMIPTERA: ALEYRODIDAE) EM COUVE TOMATE E SOJA
}

\author{
KARINA MANAMI TAKAHASHI \\ Engenheiro Agrônomo
}

Orientador: Prof. Dr. EVONEO BERTI FILHO

Tese apresentada à Escola Superior de Agricultura "Luiz de Queiroz", Universidade de São Paulo, para obtenção do título de Doutor em Ciências, Área de Concentração: Entomologia.

P I R A C I C A B A

Estado de São Paulo - Brasil

Fevereiro - 2005 
Dados Internacionais de Catalogação na Publicação (CIP) DIVISÃO DE BIBLIOTECA E DOCUMENTAÇÃO - ESALQ/USP

\section{Takahashi, Karina Manami}

Aspectos bioecológicos e potencial de parasitismo de Encarsia formosa (Gahan)

(Hymenoptera: Aphelinidae) sobre Bemisia tabaci biótipo B (Gennadius) (Hemíptera:

Aleyrodidae) em couve tomate e soja / Karina Manami Takahashi. - - Piracicaba, 2005.

73 p. : il.

Tese (Doutorado) - - Escola Superior de Agricultura Luiz de Queiroz, 2005.

Bibliografia.

1. Controle biológico (Fitossanidade) 2. Couve 3. Ecologia animal 4. Hemiptera 5. Mosca-branca 6. Ninfa 7. Parasitismo 8. Soja 9. Tomate I. Título

CDD 635.34 
"Quem conhece a sua ignorância revel a a mais profunda sapiencia. Quem ignora a sua ignorância vive na mais profunda il usão."

\section{La o - Tsé}

Aos meus pais Roque Takahashi e Madal ena Mutsumi Tanaka Takahashi que sempre foram exemplo, incentivando e apoiando nos obstáculos deste grande percurso que é viver.

DEDICO

Aos meus irmãos Leonardo susumu Takahashi e Guilherme koji Takahashi, que sempre foram amigos e sempre colaboraram de maneira incondicional no percurso desta jornada Ofereço 


\section{AGRADECIMENTOS}

À Deus, que sempre nos guia e dá forças para perseverarmos nos momentos mais difíceis.

À Escola Superior de Agricultura "Luiz de Queiroz" (ESALQ) da Universidade de São Paulo (USP) e ao Departamento de Entomologia, Fitopatologia e Zoologia Agrícola, pela oportunidade de realização do curso.

Ao Conselho Nacional de Desenvolvimento Científico e Tecnológico (CNPq), pela concessão da bolsa de estudo.

Ao Prof. Dr. Evoneo Berti Filho, pela orientação e ensinamentos acadêmicos e pela amizade e compreensão dedicados nestes anos de convivência.

Ao Pesquisador Dr. André Luiz Lourenção, pelo fornecimento de insetos para a criação de mosca branca.

Ao Prof. Dr. José Roberto Postali Parra, pela amizade, orientação e sugestões na elaboração do projeto.

Aos demais professores de Entomologia da ESALQ/USP, pelos ensinamentos, amizade e cordialidade. 
Ao Prof. Dr. Sérgio de Freitas, pela inestimável contribuição na minha formação acadêmica e pela amizade e incentivo.

A todos os colegas de Pós-Graduação, especialmente Luciano Pacelli de Macedo, Patrícia Milano, José Francisco Cruz, Simone Prado, Edmilson Silva, Maurício Godoy, Dori Edson, Uemerson Cunha, Sandra Magro, pela amizade, companheirismo e apoio.

As estudantes de graduação Bruna Barboza Rossilho e Amália Torrezan Lopes pela colaboração na execução dos experimentos, bem como pela amizade.

Aos funcionários José Carlos Rodrigues Castillho e Horozino Rodrigues dos Santos pelo auxílio na condução dos experimentos, apoio incondicional e amizade.

As amigas Simone Aparecida Fessel, Kelly Cristina Gonçalves Miyazaki, Aline Massaro Calarota, Nair Batista Nogueira e Vera Lúcia Raimundo de Oliveira que sempre estiveram ao meu lado, principalmente nos momentos mais difíceis.

A todos os funcionários da Entomologia, pela amizade, consideração e apoio na condução dos experimentos.

Serei eternamente grata a todos que, de alguma forma, contribuíram na elaboração e condução deste projeto de pesquisa. 


\section{SUMÁRIO}

RESUMO Página

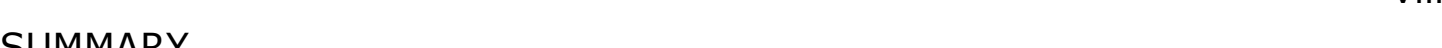

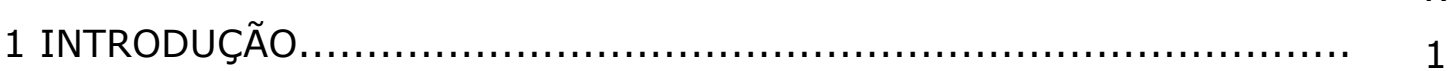

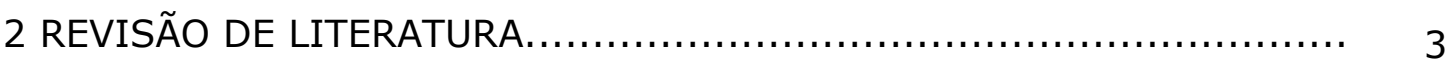

2.1 Bemisia tabaci..................................................... 3

2.1 .1 Origem e distribuição geográfica................................ 3

2.1.2 Descrição, aspectos morfológicos e ecológicos....................... 6

2.1 .3 Aspectos biológicos............................................. 9

2.1.4 Danos e importância econômica................................... 10

2.1 .5 Medidas de controle........................................... 12

2.2 Encarsia formosa................................................ 14

2.2.1 Descrição e distribuição geográfica................................. 14

2.2.2 Aspectos biológicos e ecológicos................................... 15

2.2 .3 Capacidade de busca.............................................. 18

2.2.4 O gênero Encarsia no Brasil...................................... 19

2.2.5 Controle biológico de mosca-branca por Encarsia................... 20

2.2.6 Integração de E. formosa em programas de Manejo Integrado de

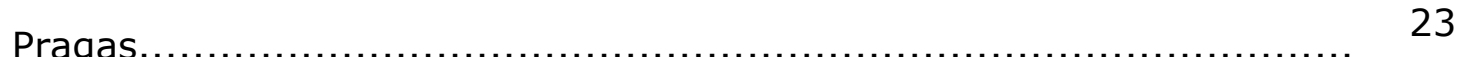

3 MATERIAL E MÉTODOS................................................ 25

3.1 Criação de manutenção de B. tabaci biótipo B........................ 25

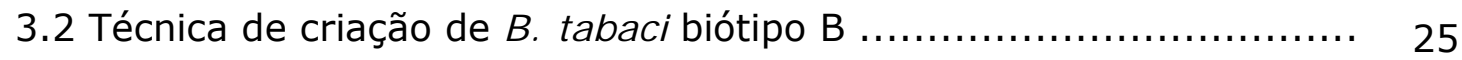


3.2.1 Avaliação dos aspectos biológicos de B. tabaci biótipo B em diferentes hospedeiros................................................... 25

3.3 Técnica de criação de Encarsia formosa............................. 27

3.3.1 Avaliação dos aspectos biológicos de E. formosa parasitanto pupas de B. tabaci biótipo $B$ oriundas de diferentes hospedeiros............ 3.3.2 Avaliação da eficiência de E. formosa sobre B. tabaci biótipo B..... 29

3.3.3 Determinação do número ideal de E. formosa a ser liberado por planta ou ninfa...........................................................

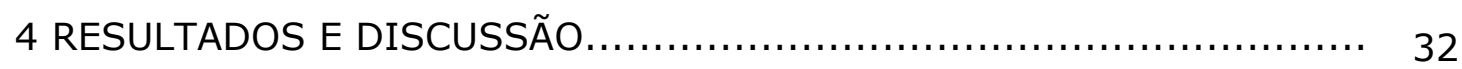

4.1 Avaliação dos aspectos biológicos de B. tabaci biótipo B em

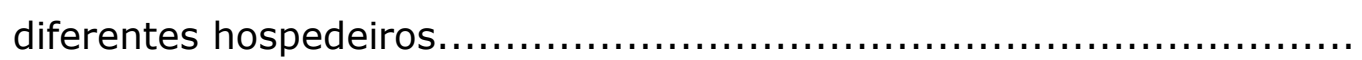

4.2 Avaliação dos aspectos biológicos de E. formosa parasitando pupas de B. tabaci biótipo $B$ oriundas de diferentes hospedeiros.

4.3 Avaliação da eficiência de E. formosa sobre B. tabaci biótipo B.

4.4 Determinação do número ideal de E. formosa a ser liberado por planta ou ninfa.

5 CONCLUSÕES. 


\title{
ASPECTOS BIOECOLÓgICOS E POTENCIAL DE PARASITISMO DE Encarsia formosa (GAHAN) (HYMENOPTERA: APHELINIDAE) SOBRE Bemisia tabaci BIÓTIPO B (GENNADIUS) (HEMIPTERA:
}

\section{ALEYRODIDAE)}

\author{
Autora: KARINA MANAMI TAKAHASHI \\ Orientador: Prof. Dr. EVONEO BERTI FILHO
}

\section{RESUMO}

O presente trabalho teve por objetivo avaliar 0 potencial de parasitismo e eficiência de E. formosa sobre B. tabaci biótipo B em couve, tomate e soja. O tempo de desenvolvimento de ovo a adulto e o número de ninfas de B. tabaci biótipo B foram avaliados em soja, tomate e couve. $O$ número de ninfas parasitadas diariamente e o número total de ninfas parasitadas por fêmeas de E. formosa até sua morte foram avaliados para determinar a capacidade de parasitismo do parasitóide. Foram realizadas liberações de números variáveis de $\mathrm{E}$. formosa para um número fixo de ninfas de $B$. tabaci biótipo $B$ para avaliar o número ideal de parasitóides por planta. Através dos resultados obtidos, observou-se que a duração de ovo a adulto de $B$. tabaci biótipo B em tomate (22,03 dias) foi estatisticamente superior a de soja (21,17 dias) e esta última significativamente superior que em couve (19,8 dias) sob as mesmas condições ambientais. O parasitóide $E$. formosa apresentou preferência por ovipositar no terceiro e quarto ínstares 
de seus hospedeiros. Comparando-se as três culturas avaliadas verifica-se que a couve apresentou número médio total de ninfas parasitadas superior aos valores obtidos para soja e tomate, que por sua vez não apresentaram diferença entre si. O parasitóide não apresentou diferença em relação à longevidade quando foram oferecidas ninfas de terceiro ou quarto ínstares nas culturas estudadas. Entretanto, verificou-se que para os dois estádios ninfais houve diferença significativa entre as culturas avaliadas. Na couve, a densidade de oito parasitóides por planta resultou em bom controle da praga. 


\section{BIOLOGICAL ASPECTS AND PARASITISM POTENCIAL OF Encarsia formosa (GAHAN) (HYMENOPTERA: APHELINIDAE) UNDER Bemisia tabaci Biotype B (GENNADIUS) (HEMIPTERA: ALEYRODIDAE)}

Author: KARINA MANAMI TAKAHSHI

Adviser: Prof. Dr. EVONEO BERTI FILHO

\section{SUMMARY}

The potencial of parasitism and the efficiency of Encarsia formosa on Bemisia tabaci were evaluated on collard green, tomato and soybean plants. The period of developmentof B. tabaci biotype B from egg to adult and the number of nymphs were evaluated on those plants. The ability of parasitism was evaluated by the number of daily parasitized nymphs and the total number of parasitized nymphs per female of E. formosa. The ideal number of parasitoids per plant was evaluated by releasing variable numbers of $E$. formosa on a fixed number of B. tabaci biotype B nymphs. The results were as follows: the duration of the egg to adult period of $B$. tabaci biotype $B$ on tomato $(22,03$ days) was statistically superior to that on soybean $(21,17$ days), while this last one was significantly superior to that on collard green $(19,8$ days), under the same environmental conditions; the parasitoid showed preference to oviposit on the third and fourth instars of $B$. tabaci biotype B nymphs; the number of parasitized nymphs on collard green was higher than those observed on soybean and tomato, whereas the numbers 
on these last one did not differ; no difference was observed as to the parasitoid longevity when third and fourth instar nymphs were offered on the tested plants; however one observe a significant difference in the mean number of parasitized nymphs; on collard green plants eight parasitoids per plant resulted in a good control of this insect pest. 


\section{INTRODUÇÃO}

A mosca-branca Bemisia tabaci (Gennadius) é um inseto polífago que causa danos severos a diversas espécies de importância econômica abrangendo o grupo das hortaliças, frutas, oleaginosas e espécies ornamentais.

No Brasil, B. tabaci biótipo B vem causando sérios problemas fitossanitários praticamente em todos os estados. As práticas agrícolas baseadas em monoculturas, juntamente com o alto potencial reprodutivo desses insetos estão entre as principais causas do surgimento deles como principal alvo de controle fitossanitário.

O controle da mosca-branca (B. tabaci biótipo B), até pouco tempo, era realizado basicamente com de inseticidas. Entretanto, a adoção desta tática de controle trouxe grandes problemas, tais como o aparecimento de resistência da praga aos inseticidas, a toxicidade e resíduos destes produtos. Assim, tem sido preconizada a utilização de alternativas no controle desta praga e uma das alternativas viáveis é o controle biológico mediante o emprego de Encarsia formosa (Gahan).

Os inimigos naturais podem representar um importante aliado no controle de insetos-praga no campo (Dent, 1995). Entretanto, com relação ao controle de $\mathrm{B}$. tabaci biótipo $\mathrm{B}$ por inimigos naturais em campo, não se tem observado efeito significativo na grande maioria dos casos, possivelmente em virtude do elevado potencial biótico da praga, além do uso excessivo de inseticidas (Prahabker et al., 1992). Alguns trabalhos, porém, têm mostrado que, em casa de vegetação, é possível o controle de 
B. tabaci com himenópteros (Heinz \& Parrella, 1994a,b). Além disso, o incremento desses inimigos naturais no campo também é possível através da utilização de inseticidas seletivos (Horowitz et al., 1994; Horowitz \& Ishaaya, 1995).

O parasitóide $E$. formosa é, provavelmente, o inimigo natural mais utilizado mundialmente para o controle de Trialeurodes (Westwood) vaporiorum e Bemisia spp. em casa de vegetação (De VIS, 2001). No Brasil, em casa de vegetação, os inimigos naturais considerados eficientes para o controle de B. tabaci são E. formosa (Arruda, 1976) e Encarsia porteri Mercet (Menezes Júnior et al., 1996).

Embora se tenha conhecimento sobre a utilização com sucesso de E. formosa no controle de aleirodídeos em casa de vegetação ao redor do mundo, pouca informação se tem sobre o desenvolvimento de métodos de criação artificial deste parasitóide (Hu et al., 2002).

$O$ presente trabalho teve por objetivos avaliar $\mathrm{O}$ potencial de parasitismo e a eficiência de E. formosa sobre B. tabaci biótipo B em couve, tomate e soja. 


\section{REVISÃO DE LITERATURA}

\subsection{Bemisia tabaci}

\subsubsection{Origem e distribuição geográfica}

Os insetos conhecidos popularmente como moscas-brancas pertencem à família Aleyrodidae e apresentam como principal gênero Bemisia, encontrandose mundialmente distribuídos. Esta espécie foi coletada pela primeira vez no fumo (Nicotiana spp.) e descrita como Aleurodes tabaci (Gennadius) na Grécia em 1889 (Russell, 1957). A distribuição geográfica de B. tabaci indica uma forte limitação pelas temperaturas frias (Lacey et al., 1999).

A espécie Bemisia tabaci (Gennadius) é cosmopolita, tendo como provável centro de origem o Oriente (Brown et al., 1995). Segundo Brown (1994) e Wool et al. (1994), devido à interferência do homem na dispersão dos insetos, uma conclusão definitiva sobre o centro de origem de B. tabaci vai se tornando cada vez mais difícil. Acredita-se, porém, que essa espécie de moscabranca seja originária do subcontinente indiano, já que nessa região há abundância e diversidade de inimigos naturais (Brown et al. 1995). Segundo estes autores, B. tabaci é um inseto multivoltino com 11 a 15 gerações por ano e tem como hábitat regiões tropicais e subtropicais. 
A mosca branca B. tabaci biótipo B é a espécie mais importante no mundo devido ao seu grande potencial de causar danos e suas características, tais como ser a única espécie da família capaz de transmitir geminivírus às plantas (Bin-Moenen \& Mound, 1990; Hilje, 1996).

Na década de 80 , o biótipo B foi registrado no continente americano, provavelmente introduzido através de plantas ornamentais importadas, sendo então disseminado para outras culturas de interesse econômico como feijão, mandioca, algodão, quiabo, melão, pimentão, abobrinha e fumo (Brown et al., 1995).

No Brasil, Costa et al. (1973) relataram o primeiro registro da ocorrência de B. tabaci em plantas de algodão no Estado do Paraná em 1968. A partir desta data, segundo Bellows et al. (1994), este inseto foi encontrado em outros estados brasileiros provocando prejuízos esporádicos. Entretanto, no início da década de 90 foram detectadas populações de mosca-branca provocando sérios prejuízos em culturas de grande valor econômico nas regiões Sudeste, Centro-Oeste e Nordeste. Lourenção \& Nagai (1994) relataram surtos populacionais de B. tabaci em hortaliças e ornamentais no Estado de São Paulo, sendo seu ataque associado ao prateamento das folhas com queda drástica de produção em aboboreira e amadurecimento irregular dos frutos em tomateiro. Segundo Schuster et al. (1990) e Yokomi et al. (1990), estes constituem sintomas característicos do ataque do biótipo B. Assim, mencionou-se a possibilidade de que um novo biótipo ou uma nova espécie teria sido introduzido no país, o que foi confirmado pela Dra. Judith Brown, da Universidade do Arizona (EUA), a partir de espécimes da mosca-branca coletados em tomateiro no Distrito Federal (França et al., 1996).

Perring et al. (1993b) admitiram a possibilidade de uma nova espécie de Bemisia em função das diferenças nos sintomas de ataque, bem como das diferenças genômicas e da incompatibilidade sexual entre $B$. tabaci biótipo A e o biótipo B. A caracterização do biótipo B como nova espécie (Bemisia argentifolii Bellows \& Perring) foi feita, de acordo com Bellows et 
al. (1994), com base nos danos característicos nas plantas hospedeiras, nas aberturas traqueais torácicas menores, no filamento de cera menor e mais frágil e na ocorrência da seta submarginal ASMS4 somente neste biótipo. Foi demonstrado que o biótipo $B$ difere de maneira expressiva do biótipo $A$, principalmente em relação ao vigor biológico, gama de hospedeiros e habilidade em transmitir viroses (Markhan et al., 1994 e Schuster et al., 1995).

Entretanto, Brown et al. (1995) revisaram o assunto e sugeriram que B. tabaci seja um complexo sofrendo mudanças evolucionárias. Atualmente, considera-se que B. argentifolii é de fato o biótipo B de B. tabaci.

A mosca-branca B. tabaci é encontrada na África, América, Ásia e região do Mediterrâneo (Coudriet et al., 1985; Murrant et al., 1988 e Vazquez et al., 1997). Atualmente, no Brasil, este inseto ocorre nos Estados de São Paulo, Minas Gerais, Goiás, Paraná, Distrito Federal, Bahia, Pernambuco (Submédio São Francisco), Ceará, Mato Grosso do Sul, Rio Grande do Norte, Tocantins e Rio de Janeiro (Villas Bôas et al., 1997).

De acordo com Brown (1994) e França et al. (1996), em alguns locais dos Estados Unidos e do Brasil onde se encontrava apenas B. tabaci biótipo A, constatou-se posteriormente somente o biótipo B. Perring et al. (1993b) explicaram esse deslocamento competitivo de corte e cópula diferenciado entre os biótipos. O biótipo A realiza essa atividade em menos de um terço do tempo gasto pelo biótipo $B$. Os machos do biótipo $B$, embora demorem mais tempo no ritual de corte com fêmeas de $A$, não efetuam a cópula, mas ao mesmo tempo impedem que o macho de $A$ o faça. Por outro lado, a cópula entre indivíduos de $B$ não é afetada, uma vez que o tempo de corte entre machos de $A$ e fêmea de B é curto.

O sucesso da dispersão de B. tabaci biótipo B deve-se à sua habilidade de adaptar-se a novas plantas hospedeiras e a condições climáticas diversas (Villas Bôas et al., 1997), à sua capacidade de desenvolver resistência a inseticidas (Prabhaker et al., 1992; Silveira, 2000) 
e de ter maior taxa de oviposição em relação a outras espécies de moscabranca (Lourenção et al., 2001).

Oliveira et al. (2001) relatam que a vasta gama de plantas hospedeiras da mosca-branca e, conseqüentemente, a sua distribuição por todos os continentes têm levado os centros de pesquisa do mundo inteiro a se organizarem em projetos de cooperação internacional para facilitar a comunicação, a pesquisa e a transferência de tecnologia.

Os hospedeiros preferenciais da mosca-branca são: cucurbitáceas (abobrinha, melancia, melão e chuchu), solanáceas (tomate, berinjela, pimentão, fumo, pimenta e jiló), brássicas (brócolos e repolho), leguminosas (feijão, feijão-vagem), algodão, mandioca, alface e quiabo, além de plantas ornamentais, daninhas e silvestres (Caballero, 1994; Melo, 1992; Villas Bôas et al., 1997).

Brown et al. (1995) afirmaram que a gama de plantas hospedeiras de Bemisia spp. tem aumentado no decorrer do tempo, o que tem sido atribuído, entre outras razões, ao uso do monocultivo irrigado. Foi constatado que a espécie $B$. tabaci biótipo A tem pouco mais de 100 plantas hospedeiras, enquanto que o biótipo B já foi encontrado em mais de 600 espécies vegetais, das quais $50 \%$ estão restritas a somente cinco famílias: Fabaceae (99 espécies), Asteraceae, Malvaceae, Solanaceae e Euphorbiaceae (Blua et al., 1995; Brown et al., 1995; De Barro, 1995; Oliveira et al., 2001).

\subsubsection{Descrição, aspectos morfológicos e ecológicos}

A mosca-branca (B. tabaci) ocorre em uma ampla faixa de plantas hospedeiras, coloniza principalmente espécies anuais e herbáceas e apresenta alto potencial reprodutivo (Brown et al., 1995).

Adultos e ninfas de $B$. tabaci ocupam preferencialmente a página inferior das folhas (local onde se alimentam), constituindo este local como principal fonte de disseminação da praga, como por exemplo, através de 
plantas ornamentais transportadas pelo homem (Ferreira \& Avidos, 1996). Sob condições favoráveis, este inseto pode apresentar de 11 a 15 gerações por ano. As fêmeas podem depositar de 100 a 300 ovos durante o seu ciclo de vida (Brown \& Bird, 1992).

Os ovos de B. tabaci são piriformes, com textura lisa e medem de 0,18 a 0,21 $\mathrm{mm}$ de comprimento e 0,06 a 0,09 $\mathrm{mm}$ de largura. Inicialmente apresentam coloração branca, mas à medida que se dá o desenvolvimento embrionário, tornam-se amarelados e próximos à eclosão adquirem coloração vermelho-clara ou café claro (Byrne \& Bellows, 1991; Eichelkraut \& Cardona, 1989; Patel, et al., 1992; Villas Bôas et al., 1997). São dispostos isoladamente ou em grupos irregulares, ou ainda, ocasionalmente, em semicírculos sendo sustentados por um pedicelo inserido na folha durante a oviposição, diretamente no tecido foliar, nunca na abertura dos estômatos (Eickelkraut \& Cardona, 1989 e Paulson \& Beardsley, 1985). Buckner et al. (2002) observaram que o pedicelo fica inserido no interior das células da epiderme, sem alcançar as células do parênquima.

$\mathrm{Na}$ fase imatura B. tabaci possui quatro ínstares, sendo o primeiro ínstar móvel e os outros imóveis nas folhas da planta. Esta mobilidade ninfal é fundamental para o ciclo de vida do inseto, pois se a folha não oferecer condições para o completo desenvolvimento ninfal, devido à senescência, por exemplo, a ninfa pode se locomover para uma folha mais adequada (Summers et al., 1996). Segundo Simmons (1999), após a eclosão, se a ninfa estiver na face adaxial, existe tendência de se locomover para a superfície abaxial, orientada mais provavelmente por um estímulo tátil ou alimentar do que por estímulos geotrópico ou fototrópico.

A ninfa de primeiro instar mede 0,24 a $0,27 \mathrm{~mm}$ de comprimento e 0,12 a $0,18 \mathrm{~mm}$ de largura. É de formato elíptico, coloração brancoesverdeada, plana ventralmente e convexa dorsalmente (Eichelkraut \& Cardona, 1989 e Patel et al., 1992). Segundo os mesmos autores, a ninfa de segundo instar é oval, e apresenta coloração branco-esverdeada e olhos 
brilhantes. Seu comprimento varia de 0,33 a 0,39 mm e sua largura de 0,18 a $0,24 \mathrm{~mm}$.

O terceiro ínstar tem formato elíptico, cor verde-pálida a verde-escura e olhos vermelhos brilhantes na parte dorsal da cabeça. É possível observar a secreção de uma substância colágena transparente saindo pelo orifício vasiforme triangular aderindo à parte posterior do abdome. Seu comprimento varia de 0,51 a 0,60 e 0,30 a 0,36 de largura (Patel et al., 1992).

A ninfa de quarto ínstar se alimenta apenas no início deste estádio, depois cessa a alimentação, quando aparentemente sofre mudanças morfológicas para se transformar em "pupa" (Eichelkraut \& Cardona, 1989). O termo "pupa" é inadequado, uma vez que o inseto não sofre qualquer tipo de metamorfose caracterizando a passagem para um novo estádio (Brown et al., 1995; Byrne \& Bellows, 1991; De Barro, 1995; Villas Bôas et al., 1997). Devido a essa peculiaridade, o tipo de desenvolvimento das moscasbrancas era denominado neometabolia para diferenciar da paurometabolia em que não ocorre essa fase de interrupção da alimentação (Zucchi et al., 1993). Atualmente, entretanto, existe tendência em se denominar qualquer metamorfose incompleta como hemimetabolia, independente da sua peculiaridade (Gallo et al., 2002).

O quarto ínstar tem formato oval, com a parte cefálica arredondada e a parte caudal terminada em uma ponta. É nítida a divisão do corpo em cabeça, tórax e abdome. O seu comprimento é de 0,54 a 0,85 mm e a largura de 0,36 a 0,60 mm. No início deste estádio, a ninfa é plana e transparente, mas no final é convexa e opaca, com os olhos vermelhos bem visíveis (Eichelkraut \& Cardona, 1989). Patel et al. (1992) acrescentam um par de setas caudais.

Os adultos de B. tabaci têm o dorso amarelo-pálido e as asas brancas, medindo de 1 a $2 \mathrm{~mm}$ de comprimento e 0,36 a 0,51 mm de largura, sendo a fêmea maior que o macho. Quando em repouso, as asas são levemente separadas, com os lados paralelos, deixando o abdome amarelado visível. 
Os olhos são vermelhos, compostos e divididos em duas partes por uma projeção cuticular. As asas têm venação reduzida e as pernas são delgadas, sendo as posteriores mais largas que as anteriores. A fêmea se diferencia do macho pelo tamanho e pela configuração da genitália (Eichelkraut \& Cardona, 1989; Patel et al., 1992 e Souza \& Vendramim, 2000).

A reprodução é sexuada dando origem somente a fêmeas ou por partenogênese arrenótoca (Byrne \& Bellows, 1991 e Eichelkraut \& Cardona, 1989). Como na maioria das espécies de mosca-branca, B. tabaci pode regular o sexo de seus descendentes, desde que tenham espermatozóides armazenados para selecionar a fertilização (Horowitz \& Gerling, 1992).

Gerling et al. (1980) relataram que este inseto fitófago tem preferência por ovipositar nas folhas mais jovens da planta hospedeira de modo que as ninfas de $3^{\circ}$ e $4^{\circ}$ ínstares (ninfas mais velhas) localizam-se na região inferior da planta, as ninfas de $1^{\circ}$ e $2^{\circ}$ ínstares (ninfas mais jovens) juntamente com os ovos na região mediana e os adultos na região superior local onde se encontram as folhas mais jovens.

\subsubsection{Aspectos biológicos}

A duração do ciclo de vida de B. tabaci varia de acordo com a planta hospedeira e a temperatura (Valle, 2001). A fase de ovo, à temperatura entre 25 e $27^{\circ} \mathrm{C}$, dura em torno de 5 a 8 dias, independentemente da planta hospedeira (Bethke et al., 1991; Liu \& Stansly, 1998; Nava-Camberos et al., 2001; Salas \& Mendonza, 1995; Tsai \& Wang, 1996 e Yee \& Toscano, 1996). Excepcionalmente, Enkegaard (1993a) observou em algodão duração desta fase em torno de 14 dias a $25^{\circ} \mathrm{C}$.

A viabilidade dos ovos é superior a $90 \%$ na faixa de temperatura entre 20 e $30^{\circ} \mathrm{C}$ (Enkegaard, 1993a; Nava-Camberos et al., 2001; Salas \& Mendonza, 1995; Tsai \& Wang, 1996; Wagner, 1995 e Wang \& Tsai, 1996). Em temperaturas acima de $30^{\circ} \mathrm{C}$ ou abaixo de $20^{\circ} \mathrm{C}$, há tendência de diminuição da viabilidade (Enkegaard, 1993a e Wang \& Tsai, 1996). 
O tempo de desenvolvimento de ovo a adulto de $B$. tabaci biótipo $B$, nas temperaturas de $20^{\circ} \mathrm{C}$ e $32^{\circ} \mathrm{C}$, foi de 36 e 14,6 dias em meloeiro e 37,9 e 16,3 dias em algodoeiro. Não houve desenvolvimento da moscabranca a qualquer temperatura acima de $35^{\circ} \mathrm{C}$ em plantas de pimenta (Nava-Camberos et al., 2001).

Villas Bôas et al. (2001) avaliaram o potencial biótico de B. tabaci biótipo $B$ em diferentes plantas hospedeiras e constataram que, no repolho e no feijão, o inseto apresentou um período pré-imaginal relativamente curto, sendo, respectivamente, de 20,5 e 21,9 dias. As maiores porcentagens de mortalidade nesses períodos foram observadas na mandioca $(97,9 \%)$ e no milho $(94,2 \%)$.

O tempo de desenvolvimento de B. tabaci é dependente da temperatura, sendo um fator imprescindível para a determinação do número de gerações. Para insetos criados em soja, em condições de laboratório, foram observados ciclos biológicos de 70,9 e 21,8 dias a $15^{\circ} \mathrm{C}$ e $30^{\circ} \mathrm{C}$, com $64 \%$ e $90 \%$ de viabilidade, respectivamente. Em condições de campo, a $30,8^{\circ} \mathrm{C}$, foi observada maior porcentagem de emergência de adultos (Albergaria \& Cividanes, 2002).

De acordo com Salas \& Mendoza (1995) o ciclo biológico de B. tabaci em folhas de tomate à $25^{\circ} \mathrm{C}$ e $65 \%$ de umidade relativa foi de ovo a adulto 22,3 dias. Para a fase de ovo foram observados 7,3 $\pm 0,5$ dias; fase de ninfa $1^{\circ}$ ínstar 4,0 $\pm 1,0$ dias, $2^{\circ}$ ínstar 2,7 $\pm 1,1$ dias, $3^{\circ}$ ínstar 2,5 $\pm 0,7$ dias, $4^{\circ}$ ínstar 5,8 0 0,3 dias; longevidade cerca de 19 dias para fêmeas e machos.

\subsubsection{Danos e importância econômica}

As moscas-brancas pertencentes ao complexo Bemisia vêm causando sério impacto na agricultura mundial. Estimam-se em bilhões de dólares os danos (diretos e indiretos) causados por estes insetos às mais variadas plantas cultivadas e espécies ornamentais (Brown et al., 1995; Perring et al., 1993a). 
Nas últimas três décadas, B. tabaci causou perdas expressivas em culturas anuais em todo o mundo. Sua alimentação direta e a excreção de "honeydew" afetaram o rendimento e a qualidade das lavouras (Ellsworth, 1999).

A mosca-branca B. tabaci têm sido relatada como uma importante praga em mais de 600 espécies de plantas cultivadas e daninhas, e como vetor de 70 vírus de plantas em países tropicais e sub-tropicais, incluindo "tobacco leaf curl", "cassava mosaic" e "cucumber yellows" (Brunt, 1986; Hunter \& Poston 2001). O controle de B. tabaci é um desafio em virtude de sua movimentação entre cultivos, alto potencial reprodutivo, ampla gama de hospedeiros, resistência a inseticidas e pelo fato de habitar a superfície inferior das folhas (Antony et al., 2003).

Nos EUA, B. tabaci biótipo B, entre 1991 e 1992, causou perdas estimadas em, aproximadamente, 200 e 500 milhões de dólares na região da Califórnia e entre 1991 a 1995, mais de 100 milhões de dólares anuais (Toscano et al., 1998). A mosca-branca sozinha ocasionou perdas nos EUA que excederam 500 milhões de dólares em 1991 (Perring et al., 1993a), dos quais 141 milhões foram em tomate na Flórida na safra de 1990-1991 (Schuster et al., 1996).

Segundo Medina Esparza \& Leon Paul (1994), no México, entre 1991 e 1992, as perdas causadas pela mosca-branca em lavouras de melão, melancia, gergelim e algodão excederam a 33 milhões de dólares, reduzindo substancialmente as áreas cultivadas na região conhecida como Vale do México.

Na América Central e no Caribe, grandes perdas foram verificadas em cultivos de tomateiro, quiabeiro, algodoeiro, tabaco e meloeiro em Cuba, Barbados, Jamaica, Monsenhor, Nicarágua e Santa Lúcia (Hilje, 1996; Vazquez, 1999).

A mosca branca B. tabaci biótipo B, vem causando sérios problemas no Brasil desde 1995. As perdas ocasionadas por esta praga chegaram a mais de cinco bilhões de dólares, principalmente em cultivos de feijoeiro, 
tomateiro, algodoeiro, meloeiro e algumas hortaliças (Lima et al., 2000; Oliveira et al., 2001).

O dano direto ocorre devido à sucção contínua de seiva elaborada do floema ocasionando o definhamento da planta. O dano indireto deve-se à transmissão de viroses para a planta hospedeira no ato da sucção da seiva, podendo conduzir a planta à morte. Além disso, este inseto, devido ao seu hábito de alimentação, produz o "honeydew" que muitas vezes deposita-se na superfície das folhas e frutos, tornando-os ambiente favorável para o desenvolvimento de fungos (Capnodium), acarretando a fumagina. Com isso, tem-se a redução da área fotossinteticamente ativa das folhas reduzindo a produção e a qualidade de frutos na planta (Hilje, 1996; Fernandes, 1998).

No Brasil recentemente a mosca-branca tem causado sérios prejuízos em várias culturas de importância sócio-econômica como melão, uva, tomate, espécies ornamentais como bico-de-papagaio, crisântemo e roseiras, entre outras. Estima-se que os prejuízos causados por este inseto no Brasil já atingiram a cifra de 100 milhões de reais (Ferreira \& Avidos, 1996).

\subsubsection{Medidas de controle}

Segundo Riley \& Palumbo (1995) e Palumbo et al. (2001), o controle de B. tabaci resume-se, principalmente, à aplicação de inseticidas visando o controle populacional deste inseto. Nos Estados Unidos, no Arizona e no sudoeste da Califórnia, grandes populações de B. tabaci biótipo B desenvolvem-se nos meses de verão e levam a utilização extensiva de inseticidas para o controle desta praga em algodão (Ellsworth \& Jones, 2001 e Ellsworth \& Martinez-Carrillo, 2001).

Os tratamentos químicos são, na maioria dos casos, de caráter preventivo e/ou curativo não se baseando em critérios populacionais do inseto. De maneira geral, inseticidas de largo espectro de ação são 
utilizados, desconsiderando-se os impactos decorrentes da utilização exclusiva do controle químico, como o surgimento de populações da moscabranca resistentes a inseticidas (Gerling \& Sinai, 1994; Liu \& Stansly, 1997).

A espécie B. tabaci biótipo $B$ é particularmente propensa a desenvolver resistência a inseticidas, sendo que a resistência da praga a organofosforados, carbamatos e piretróides já foi relatada (Costa \& Brown, 1991; Cahill et al., 1995). A maioria dos sistemas de manejo de pragas fundamentam-se no uso de inseticidas, o que consequentemente acarreta dano ao complexo de inimigos naturais. As táticas utilizadas para controlar os insetos em agroecossistemas deveriam contribuir para a sustentabilidade do sistema e para a qualidade ambiental (Higley \& Pedigo, 1997). De maneira que a base desta visão de manejo de insetos na agricultura é a conservação dos inimigos naturais e seus efeitos benéficos na regulação das populações de insetos-praga.

Revisões recentes catalogaram 114 espécies de artrópodes predadores, aproximadamente 50 espécies de parasitóides e 11 espécies de fungos, de ocorrência natural, associados com B. tabaci ao redor do mundo (Faria \& Wraight, 2001 e Gerling et al., 2001). Rao et al. (1989) mostraram que o parasitismo de ninfas de B. tabaci por parasitóides da família Aphelinidae, alcançou $40 \%$ em dois anos em cultivos de algodão que não receberam tratamento químico.

Segundo Gerling et al. (2001), o controle biológico de B. tabaci tem sido realizado basicamente através da utilização de himenópteros parasitos dos gêneros Encarsia Foerster e Eretmocerus Haldeman (Hymenoptera: Aphelinidae). A introdução de parasitóides exóticos e a conservação de parasitóides exóticos e endêmicos constituem tentativas que têm sido utilizadas para o controle de populações de Bemisia em campo (Goolsby et al., 1998; Henneberry et al., 1998).

A utilização de inimigos naturais dentro do programa de Manejo Integrado de Pragas (MIP) para B. tabaci biótipo $B$, reduziria a resistência da praga a inseticidas e forneceria maior sustentabilidade no sistema de 
controle da mosca-branca para o cultivo. O parasitóide E. formosa strain Beltsville foi identificado como um inimigo natural potencialmente efetivo para o controle de $\mathrm{B}$. tabaci através de liberações inundativas em casa de vegetação (Heinz \& Parrellla, 1994b; Van Lenteren \& Brasch, 1994).

Segundo Manzano et al. (2003), sob práticas agrícolas atuais, a utilização de parasitóides poderia ser combinada com métodos de controle químico com a finalidade de reduzir a população de mosca-branca e o dano ao cultivo. O objetivo deveria ser reduzir a população da praga no início do cultivo através do uso de inseticidas seletivos que não prejudicassem os inimigos naturais.

Jazar \& Hammad (2004), avaliando a eficiência de vários agentes de controle biológico contra B. tabaci em tomate, concluíram que o manejo da praga usando inimigos naturais surge como uma ferramenta promissora para utilização em programas de MIP. Os autores concluíram que o uso integrado de Encarsia formosa e Verticillium lecanii é possível quando as condições ambientais desfavorecem um destes inimigos naturais. Dessa forma, em dias úmidos, com umidade relativa elevada, recomenda-se utilizar V. lecanii através da aplicação de Mycotal ${ }^{\circledR}$ e em dias quentes e secos deve-se usar E. formosa.

\subsection{Encarsia formosa}

\subsubsection{Descrição e distribuição geográfica}

O parasitóide E. formosa pertence à família Aphelinidae e foi descrito em 1924 por Gahan de espécimes coletados em Idaho, USA (Gahan, 1924). O gênero Encarsia apresenta mais de 200 espécies, sendo a maioria parasitóides de moscas-brancas e cochonilhas de carapaça (Polaszek et al., 1992; Van Lenteren et al., 1997). O gênero Encarsia compreende parasitóides que se desenvolvem em hospedeiros pertencentes às famílias 
Diaspididae e Aleyrodidae (Viggiani \& Mazzone, 1979), com exceção da espécie Encarsia partenopea Masi (Gerling, 1990).

Dentre os agentes de controle biológico de moscas-brancas estudados, E. formosa constitue um dos mais promissores. É um endoparasitóide solitário e telítoco, sendo que cada geração consiste inteiramente de fêmeas (Doutt, 1959). Segundo Hoddle et al. (1998), o parasitóide E. formosa é um inseto mundialmente utilizado para o controle de mosca-branca em cultivos de vegetais e ornamentais em casas de vegetação.

A bionomia de E. formosa sugere origem tropical ou subtropical, visto que esta não deve ser de localização distante do centro de origem de seu hospedeiro. A ocorrência deste parasitóide foi registrada na Europa, Austrália, Nova Zelândia, Canadá e Estados Unidos (Vet et al., 1980).

A fêmea de E. formosa mede em torno de $0,6 \mathrm{~mm}$, possui cabeça de coloração marrom escura e tórax preto, com os lados amarelos. O abdome é amarelo brilhante, provido de um ovipositor que se estende além da extremidade do corpo. Possui antenas marrom-claras, com oito antenômeros e medindo 0,5 mm de comprimento. As asas são hialinas, cobertas regularmente com pêlos curtos e franjas com longos pêlos (1,5 mm de extensão). Os machos são maiores, possuem antenas mais largas, com sete a oito antenômeros, e abdome marrom-escuro (Vet et al., 1980).

\subsubsection{Aspectos biológicos e ecológicos}

A reprodução de $E$. formosa ocorre, usualmente, por partenogênese telítoca (Vet et al., 1980; Gerling, 1983). O parasitismo secundário, característica da família Aphelinidae, representa desvio nas ligações tróficas de machos e fêmeas, chamado desenvolvimento diferencial dos sexos ou ditroficidade sexual (Yasnosh, 1979). Ocorrendo, assim, um autoparasitismo ou adelfoparasitismo obrigatório, no qual os machos desenvolvem-se como hiperparasitóides das fêmeas de sua própria espécie (Viggiani, 1987; 
Yoshimoto, 1984). Segundo Gerling (1966), o ovo que dá origem a um macho, desenvolve-se dentro da larva da sua espécie.

Nesta espécie, a reprodução é mediada por infecções da bactéria Wolbachia, com as fêmeas maturando de 8 a 10 ovos por dia (Zchori-Fein et al., 1992). As taxas diárias de maturação de ovos e oviposição diminuem com a idade do parasitóide. Os adultos obtêm energia consumindo "honeydew" ou mesmo hemolinfa dos hospedeiros, os quais, neste caso, são perfurados pelo ovipositor das fêmeas, sem que haja a deposição de ovos (Gerling, 1966 e Hoddle et al., 1998). Os hospedeiros utilizados para alimentação não são parasitados, assim como não foi observada alimentação em hospedeiros parasitados (Van Lenteren et al., 1980).

O parasitóide apresenta ovos himenopteriformes e sésseis, três estádios larvais, pupa e adulto (Viggiani, 1987). Nechols \& Tauber (1977) citam um ciclo de vida de 16 a 23 dias e afirmam que o período de desenvolvimento do ovo e da larva diminuem progressivamente, quando estádios mais velhos da mosca-branca são atacados.

O limite térmico inferior que não interrompe o desenvolvimento dos estádios imaturos do parasitóide varia de $10,5{ }^{\circ} \mathrm{C}$ a $13,3{ }^{\circ} \mathrm{C}$ (Enkegaard, 1993a; Osborne, 1982).

De acordo com Shisheibor \& Brennan et al. (1995), o tempo para desenvolvimento de ovo a adulto de E. formosa parasitando ninfas de Trialeurodes ricinus variou de 17,7 a 19,3 dias quando a mosca-branca foi criada em plantas de algodão e de feijão, respectivamente. A fecundidade e a longevidade de adultos podem ser afetadas positivamente pelo tamanho do hospedeiro no qual o parasitóide se desenvolveu, sendo que hospedeiros maiores resultam em maiores taxas de fecundidade e longevidade (Hoddle et al., 1998).

A longevidade dos adultos E. formosa não está correlacionada com o tamanho do corpo, diminuindo com o aumento da temperatura, apresentando valor máximo de 52 dias à $20{ }^{\circ} \mathrm{C}$ (Van Lenteren et al., 1987). A carga de ovos, o número de ovos maduros disponíveis ao parasitóide para 
oviposição e o tamanho dos insetos hospedeiros disponíveis influenciam em algumas espécies de Encarsia a frequência de utilização dos hospedeiros para nutrição ou reprodução (Minkenberg et al., 1986).

O tempo de desenvolvimento, a taxa de mortalidade de formas imaturas de E. formosa e a taxa de parasitismo dos adultos são influenciadas pela espécie de mosca-branca na qual o parasitóide se desenvolveu, bem como pela planta hospedeira utilizada pela mosca-branca (Hoddle et al.,1998). Os adultos de E. formosa apresentam preferência para ovipositar em ninfas de terceiro e quarto ínstares de B. tabaci e Trialeurodes vaporariorum (Nechols \& Tauber, 1977; Ennkegaard, 1993a).

A utilização de ninfas mais jovens de B. tabaci biótipo B para oviposição por adultos de E. pergandiella retardou o desenvolvimento dos parasitóides, provavelmente para permitir o desenvolvimento da moscabranca hospedeira até o terceiro ínstar, garantindo uma fonte adequada de recursos para o desenvolvimento larval (Liu \& Stansly, 1997). O desenvolvimento de formas imaturas de E. formosa é limitado pela temperatura. Os limites inferior e superior de temperatura para o desenvolvimento de formas imaturas de E. formosa são respectivamente 10,5 ${ }^{\circ} \mathrm{C}$ e 38,30 $\mathrm{C}$ (Enkegaard, 1993a; Osborne, 1982).

O período de ovo até a emergência do adulto requer 188,9 a 207 graus dia no limite térmico inferior, sendo que o desenvolvimento pode ser mais rápido sob temperaturas flutuantes (Enkegaard, 1993a; Osborne, 1982; Stenseth, 1975).

A dispersão dos adultos de E. formosa não ocorre no período noturno. A atividade de vôo dos adultos apresenta picos no início da tarde devido à influência positiva da presença de luz e da temperatura sobre a capacidade de dispersão do parasitóide (Hoddle et al.,1998). Jiang et al. (1999) verificaram que E. formosa mostrou forte relação com a distribuição espacial e temporal do hospedeiro T. vaporariorum.

Quando o número de ninfas de T. vaporariorum aumenta, a proporção de ninfas atacadas por indivíduo de E. formosa diminui, refletindo assim, em 
uma resposta funcional do tipo II. Respostas funcionais do tipo II têm sido observadas em laboratório para Trialeurodes ricini Misra e para T. vaporiorum, B. tabaci e B. argentifolii em laboratório e casa de vegetação (Enkegaard, 1994; Fransen \& van Montfort, 1987; Perera, 1982; Shishehbor \& Brennan, 1996; Yano, 1987). A resposta funcional de E. formosa é afetada pela temperatura (Enkegaard, 1994), resíduos sub-letais de inseticidas nas folhas (Perera, 1982), número de parasitóides presente (Yano, 1987), carga de ovos, sucesso na oviposição, e atividade de forrageamento (Van Roermund \& Van Lenteren, 1992a).

\subsubsection{Capacidade de busca}

O sucesso reprodutivo de $\mathrm{E}$. formosa que reflete as taxas de parasitismo alcançadas pelo parasitóide depende, necessariamente, da capacidade do forrageamento do inseto hospedeiro (mosca-branca). Para que tal objetivo seja alcançado, é necessário que as fêmeas adultas de $\mathrm{E}$. formosa localizem e avaliem a viabilidade de uso da presa, além de utilizarem as ninfas de mosca-branca de forma apropriada (Hoddle et al., 1998).

A análise do comportamento de forrageamento de $E$. formosa revela que este parasitóide procura e encontra seus hospedeiros de maneira totalmente aleatória, não existindo nenhum sinal visual ou olfativo envolvido neste processo. A taxa com que o adulto do parasitóide encontra ninfas do hospedeiro depende da velocidade de caminhamento do parasitóide, do tamanho das moscas-brancas e do número de hospedeiros em uma folha. A atividade de caminhamento do parasitóide na folha pode ser dividida em períodos nos quais o parasitóide se encontra andando, totalmente parado ou executando vôos curtos sobre folha. Estes vôos curtos são conhecidos como "saltos". A velocidade de caminhamento por sua vez é influenciada por variáveis como o tipo de venação da folha, a presença e quantidade de 
tricomas, o excesso de "honeydew" na folha, entre outros (Sütterlin \& Van Lenteren, 1997).

O tempo de residência do parasitóide na folha também é muito importante. Uma vez encontrado o hospedeiro ou evidências da passagem do hospedeiro pela folha ("honeydew", exúvias de mosca-branca, hospedeiros parasitados e oviposição em hospedeiros não parasitados), ocorre um aumento no tempo de residência do parasitóide na folha (Van Roermund \& Van Lenteren, 1995).

Segundo Van Lenteren et al. (1995), a variação na pilosidade de folhas de hortaliças pode influenciar o padrão e comportamento de caminhamento do parasitóide E. formosa. Para estudar a influencia da pilosidade (forma e densidade de pelos) sobre a eficiência de E. formosa, Sütterlin \& Van Lenteren (1997) utilizaram cultivares da espécie ornamental Gerbera jamensoni. Segundo os autores, a presença de pelos nas folhas de G. jamensoni afetou a velocidade de caminhamento de E. formosa. Entretanto, a variação na densidade e forma dos pelos entre os cultivares testados não afetou significativamente a velocidade e o padrão de caminhamento dos parasitóides.

Além disso, fatores como temperatura e hora do dia também podem afetar a atividade de forrageamente de E. formosa (Simmons \& McCutcheon, 2001; Simmons et al., 2002).

\subsubsection{O gênero Encarsia no Brasil}

No Brasil, em virtude das moscas-brancas (complexo Bemisia) terem se tornado sério problema fitossanitário há apenas alguns anos, os estudos envolvendo os parasitóide do gênero Encarsia ainda se encontram restritos aos levantamentos para detecção da ocorrência destes insetos na entomofauna. Oliveira et al. (1999) realizaram levantamento faunístico detectando a presença de parasitóides do gênero Encarsia e alguns predadores de moscas-brancas na região de Brasília. Moreira et al. (1999) 
identificaram a ocorrência de parasitismo de mosca-branca por Encarsia lutea nas culturas do tomate e uva nas localidades de Juazeiro-BA e Petrolina-PE.

\subsubsection{O controle biológico de mosca-branca por Encarsia}

Vespas parasitas dos gêneros Amitus, Encarsia e Eretmocerus encontram-se entre os mais importantes inimigos naturais do complexo de B. tabaci (Cock, 1986; Hoelmer, 1995). Estudos conduzidos por Heinz \& Parrella (1998) mostraram que a porcentagem de parasitóides que se tornaram adultos foi maior para Encarsia do que para Eretmocerus, independente do hospedeiro. O gênero Encarsia compreende mais de 170 espécies que se encontram mundialmente distribuídas (Hayat, 1989).

O parasitóide E. formosa é utilizado no mundo todo para o controle de moscas-brancas em casa de vegetação (Van Lenteren et al., 1996 e Van Lenteren \& Woets, 1988). O uso comercial do parasitóide iniciou-se na Europa na década de 20. Acredita-se que a primeira criação massal de E. formosa para o controle de T. vaporariorum tenha ocorrido em 1927 na Inglaterra e perto de 1930 foram produzidas anualmente 1,5 milhões de ninfas da praga parasitadas que eram distribuídas nas folhas de tomate. Porém, a partir de 1945 o interesse diminuiu em virtude do desenvolvimento de inseticidas sintéticos e também da ausência de métodos para a utilização do parasitóide. Entretanto, o interesse pelo parasitóide voltou após o desenvolvimento do controle biológico de Tetranychus urticae Koch e quando a resistência da mosca-branca em casa de vegetação foi relatada (Hussey et al., 1965; Speyer, 1930; Wardlow et al., 1976).

Após 1970, a utilização do parasitóide reiniciou-se e expandiu de 100 para 4800 hectares de casas de vegetação em 1993 (Van Lenteren, 1995, Van Lenteren \& Hulpas-Jordaan, 1987; Van Lenteren \& Woets, 1988). Comparando a área de casa de vegetação em várias partes do mundo com a área onde são utilizados agentes de controle biológico, tem-se que os 
lugares onde E. formosa é mais utilizado encontram-se na Europa e Rússia e as maiores concentrações de cultivos protegidos onde o parasitóide é utilizado extensivamente estão na América do Norte e Ásia, particularmente no Japão (Van Lenteren, 1995).

Nos programas de controle biológico de moscas-brancas por E. formosa em casas de vegetação, fatores físicos como a temperatura do local de liberação e o espaçamento tem afetado a dinâmica parasitóidehospedeiro. Do mesmo modo, fatores relacionados à planta como, por exemplo, a espécie da planta, estado nutricional, variedade, número e tipo de tricomas também podem afetar a eficácia de E. formosa diminuindo o parasitismo (Bentz et al., 1996; Hoddle et al., 1998).

O fumo é a planta hospedeira mais comumente utilizada para a produção comercial do parasitóide E. formosa (Ravensberg, 1991). Inicialmente, ninfas parasitadas de T. vaporariorum eram distribuídas nas plantas a serem controladas. Entretanto, problemas associados com esta prática, como por exemplo, a distribuição de pragas e doenças nas folhas, levaram ao desenvolvimento de outros métodos de distribuição. As ninfas de mosca-branca parasitadas passaram a ser removidas das folhas através de escovação ou lavagem e coladas em cartões (Speyer, 1930; Scops, 1971; Popov, 1987).

Os insucessos no controle biológico utilizando-se E. formosa têm sido atribuídos ao uso de parasitóides de baixa qualidade (van Lenteren, 1993), bem como, as diferenças ente o número de parasitóides solicitados para as empresas que produzem inimigos naturais e o número recebido, afetando assim as taxas de liberação (Sanderson \& Ferrentino, 1992). Testes de controle de qualidade para o parasitóide têm sido realizados com a finalidade de determinar se a criação massal do inimigo natural pode afetar sua eficiência após liberação em casa de vegetação (Van Lenteren, 1991; Van Lenteren et al., 1996).

Nas culturas do algodão, soja, couve-flor e tomate (estudos realizados no Egito) o parasitóide E. lutea mostrou-se capaz de parasitar a mosca- 
branca, B. tabaci, durante todos os meses do ano, atingindo maiores taxas de parasitismo, entre 23-68\%, principalmente durante verão (Abdel Fattah et al., 1987). Gerling (1986), em revisão sobre os inimigos naturais de B. tabaci, destaca a importância de E. lutea e Eretmocerus mundus como importantes agentes de controle biológico dessa praga.

Vários estudos demonstram que E. formosa apresenta grande potencial no controle de moscas-branca em casa-de-vegetação em bico-depapagaio (Lindquist, 1988). Parrella et al. (1991), estudando o controle biológico de B. tabaci em cultivo comercial de bico-de-papagaio sob estufa, concluíram que o parasitóide E. formosa, liberado semanalmente, na quantidade de 3 a 5 insetos por planta, foi responsável por elevadas taxas de mortalidade, chegando a atingir o índice de 58,2 $\pm 9,8 \%$ de parasitismo. A utilização dessa estratégia de liberação associada a pulverizações de detergente quando necessário e retirada manual de ramos intensamente atacados foram suficientes para proporcionar bom controle da praga.

Estudos realizados também com bico-de-papagaio em casa-devegetação utilizando o strain Beltsville de E. formosa para o controle de B. tabaci, biótipo B evidenciaram que liberações semanais de um ou três parasitóides por planta resultaram em ótimos níveis de controle da praga, com melhores resultados para a maior densidade de liberação, atingindo eficiência semelhante à de cultivos comerciais com aplicação de inseticidas (Hoddle et al., 1997a). Em trabalho semelhante, estudando a liberação das mesmas densidades de E. formosa (1 ou 3 parasitóides/planta/semana), Hoddle et al. (1997b) mostraram que pode ocorrer uma situação inversa, sendo mais eficiente a liberação de menor quantidade de parasitóides resultando em maiores taxas de mortalidade. Altas densidades populacionais de E. formosa, principalmente quando as plantas são pequenas, podem favorecer a ocorrência de interferência mutua entre os parasitóides, levando a menor taxa de parasitismo. 
Heinz \& Nelson (1995) verificaram que as combinações dos parasitóides E. formosa, E. pergandiella e do predador Delphastus pusilus resultaram em significantes níveis de controle de $\mathrm{B}$. tabaci biótipo $\mathrm{B}$.

\subsubsection{Integração de E. formosa em programas de Manejo Integrado de Pragas}

O uso de $\mathrm{E}$. formosa pode requerer a integração com outros métodos de controle de pragas. Técnicas que utilizam liberações de $E$. formosa podem necessitar serem combinadas com outras táticas, como o controle cultural, o uso de outros agentes de controle biológico e a aplicação de inseticidas (Hoddle et al., 1998).

Os principais métodos de controle cultural que podem ser combinados com liberações de E. formosa são a inspeção de mudas, sanidade, monitoramento e uso de armadilhas amarelas. A inspeção de mudas é realizada com o objetivo de identificar plantas infestadas antes da introdução destas na casa de vegetação. A sanidade, como por exemplo o controle de plantas daninhas e a retirada de plantas infestadas, elimina fontes de refúgio para a mosca-branca (Van Veire, 1985; Webb \& Smith, 1980).

Outros inimigos naturais de moscas-brancas têm sido estudados como agentes que podem ser combinados com liberações de E. formosa a fim de aumentar a eficácia do controle biológico de mosca-branca. Os agentes de controle biológico que podem ser usados em combinação com E. formosa incluem diversas espécies de fungos entomopatogênicos e insetos predadores. Dentre as espécies de fungo, Aschersonia aleyrodis é a espécie que tem recebido maior atenção (Fransen, 1994; Fransen \& Van Montfort, 1987). Esta espécie parece ser compatível com o parasitóide, pois a seletividade do fungo têm sido observada em esporos do fungo que não infectam moscas-branca parasitadas contendo parasitóides imaturos mais velhos que três dias. Além disso, o parasitóide raramente oviposita em 
ninfas da praga infectadas com o fungo (Fransen \& Van Lenteren, 1994). Outras espécies de fungo de interesse para utilização conjunta com o parasitóide incluem Verticillium lecanii e Paecilomyces fumosoroseus (Rombach \& Gillespie, 1988; 1988; Van Veire \& Degheele, 1996). Na Europa, E. formosa tem sido utilizado com o mirídio Macrolophus caliginosus até que o predador exerceu um efeito no crescimento populacional da mosca-branca (Sampson \& King, 1996). Outro predador, o coccinelídeo Delphastus pusillus tem sido avaliado para compatibilidade com o uso de $\mathrm{E}$. formosa e foi eficiente na redução de altas densidades da praga (Heinz \& Nelson, 1995). 


\section{MATERIAL E MÉTODOS}

\subsection{Criação de manutenção de Bemisia tabaci.}

A população inicial de mosca branca, obtida no IAC (Instituto Agronômico de Campinas), foi mantida em casa de vegetação com tela antiafídeo $(0,2 \times 0,2 \mathrm{~mm})$. No IAC, vem sendo mantida há vários anos uma criação de B. tabaci biótipo B, cuja identificação inicial foi feita pela Dra. Judith K. Brown, Universidade do Arizona. Periodicamente é realizada a confirmação dessa identidade através da introdução de plantas de abóbora na criação da mosca-branca, cuja indução de prateamento das folhas é específico deste biótipo.

Plantas hospedeiras (soja, tomate e couve) foram cultivadas em vasos e substituídas a cada sete dias. Diariamente foi observada a presença de inimigos naturais que foram eliminados a fim de manter a população de mosca branca isenta deles.

\subsection{Técnica de criação de B. tabaci biótipo B}

\subsubsection{Avaliação dos aspectos biológicos de B. tabaci biótipo B em diferentes hospedeiros}

Foram infestadas 30 plantas de cada cultura avaliada (couve, soja e tomate) com 30 adultos de $B$. tabaci biótipo $B$, coletados através de sugador e mantidos em canudos plásticos fechados com algodão (Figura 1). 
Os canudos plásticos foram transferidos para as plantas, mantidos em gaiolas de plástico (Figura 2), onde foram liberados

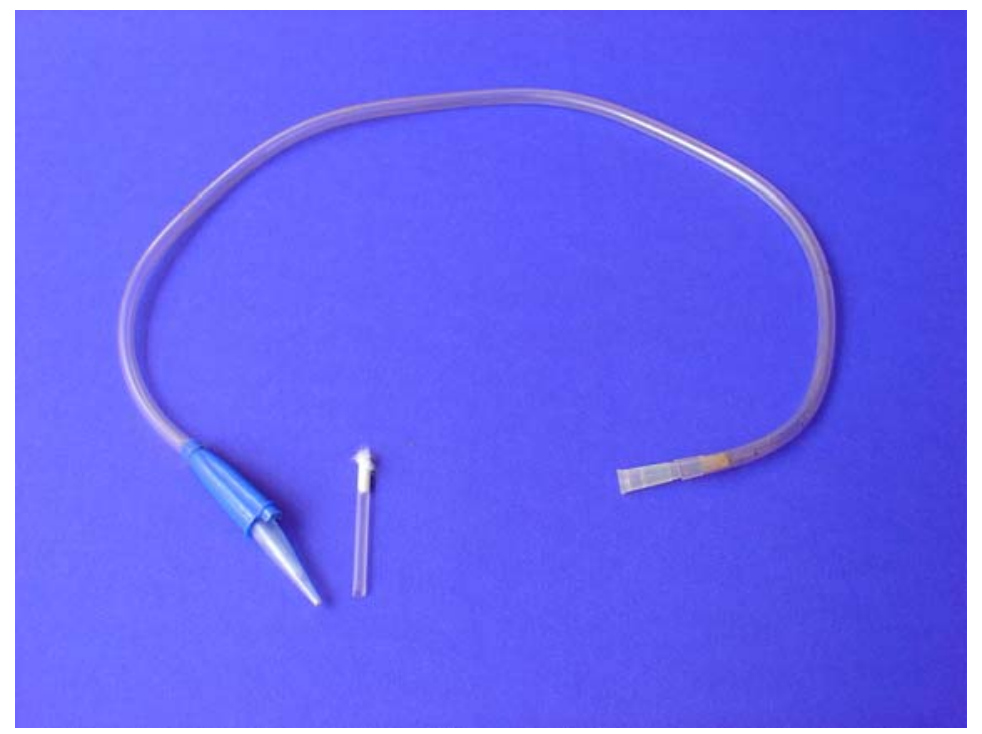

Figura 1 - Sugador utilizado para captura de B. tabaci biótipo B e canudo plástico onde os insetos foram mantidos

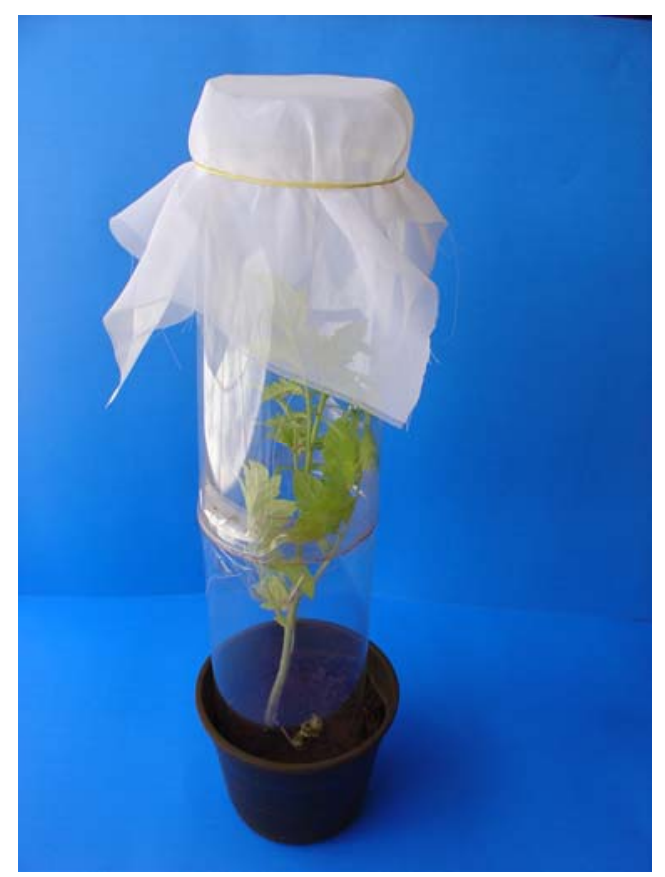

Figura 2 - Planta mantida em gaiola de plástico 
Após 48 horas, foram retiradas as gaiolas e selecionados 30 ovos da praga em cada cultura avaliada. Foram avaliados 0 tempo de desenvolvimento de ovo a adulto, bem como o número de ninfas de $\mathrm{B}$. tabaci biótipo B em cada planta estudada. O delineamento experimental foi inteiramente casualizado e os resultados foram analisados através de análise de variância, sendo as médias comparadas pelo teste de Tukey ao nível de $5 \%$ de probabilidade.

\subsection{Técnica de criação de Encarsia formosa}

\subsubsection{Avaliação dos aspectos biológicos de E. formosa parasitando pupas de B. tabaci biótipo B oriundas de diferentes hospedeiros.}

Inicialmente foram infestadas plantas de soja, tomate e couve com 30 adultos de $B$. tabaci biótipo $B$ por planta. As folhas contendo trinta ninfas de primeiro, segundo, terceiro e quarto ínstares de B. tabaci biótipo B foram retiradas. Estas folhas, contendo ninfas, foram recortadas em discos de $\mathrm{mm}$ de diâmetro e colocadas em placas de plástico tampadas de $6 \mathrm{~cm}$ de diâmetro e $2 \mathrm{~cm}$ de altura (Figura 3) contendo ágar e nipagin.

Um casal de E. formosa foi colocado em cada placa de plástico por 24 horas, sendo realizadas 30 repetições para cada ínstar de B. tabaci biótipo B em todas as plantas estudadas. As placas foram mantidas em laboratório à $25^{\circ} \mathrm{C}, 70 \pm 10 \%$ e 14 horas de fotofase. 


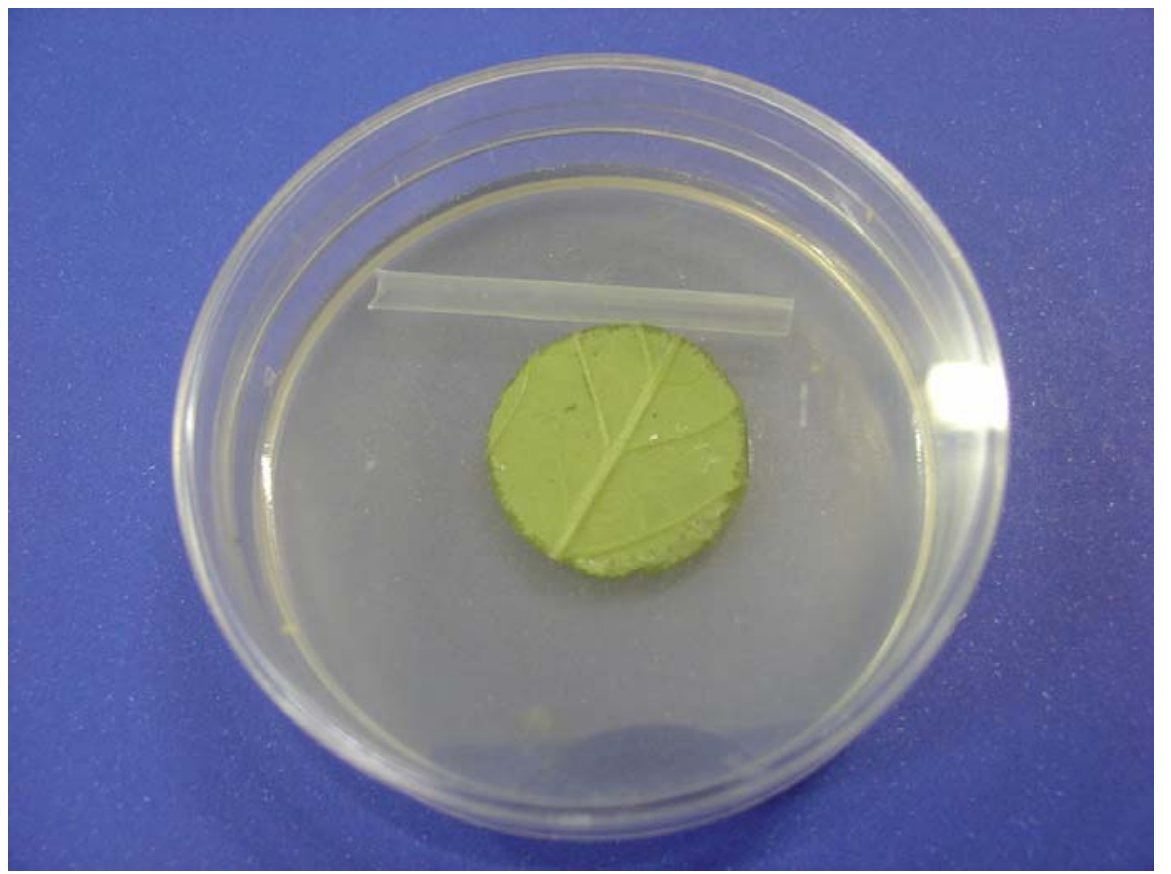

Figura 3 - Placa de plástico $6 \times 2 \mathrm{~cm}$

Foram realizadas observações diárias, sendo avaliado o ciclo total de E. formosa parasitando os quatro ínstares ninfais de $\mathrm{B}$. tabaci biótipo $\mathrm{B}$. Além disso, para cada cultura foram avaliados as porcentagens de parasitismo e o número de parasitóides emergidos.

O delineamento experimental foi inteiramente casualizado em esquema fatorial $4 \times 3$ com 30 repetições. Os tratamentos foram os ínstares ninfais de B. tabaci biótipo B nas culturas de couve, tomate e soja. Para analisar o efeito de cada fator, foi realizada análise de variância (teste F) a $5 \%$ de probabilidade, comparando as médias entre os estádios ninfais da praga e as culturas avaliadas. 


\subsubsection{Avaliação da eficiência de E. formosa sobre B. tabaci biótipo B}

A capacidade de parasitismo de E. formosa foi avaliada utilizando-se parasitóides emergidos em tomate, soja e couve.

O experimento foi conduzido com o objetivo de avaliar o potencial de utilização de E. formosa em liberações massais para o controle de B. tabaci biótipo B. Assim, trinta fêmeas recém-emergidas foram isoladas em tubos de vidro $(8,0 \times 2,5 \mathrm{~cm})$ e foram oferecidas diariamente e até a morte destas, cerca de 20 ninfas de terceiro e quarto ínstares de B. tabaci biótipo B. Após serem submetidas ao parasitismo por 24 horas, as folhas contendo ninfas da praga foram transferidas para placas de plástico (Figura 4), adotando-se o mesmo procedimento utilizado no item 3.3.1.

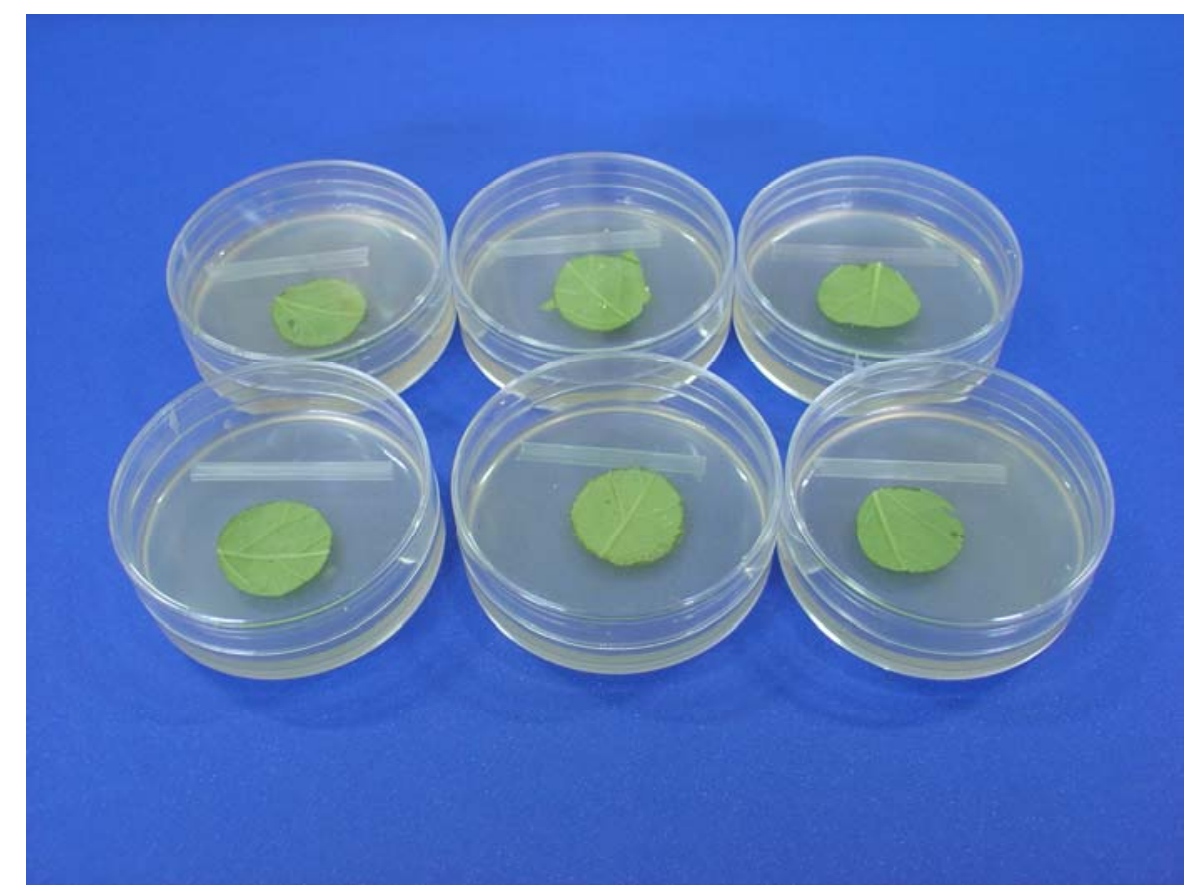

Figura 4 - Placas de plástico contendo folhas com ninfas de B. tabaci biótipo B 
Foram observados os seguintes parâmetros: número de ninfas parasitadas diariamente e número total de ninfas parasitadas sob condições laboratoriais de $25 \pm 2^{\circ} \mathrm{C}$ de temperatura, $70 \pm 10 \%$ de umidade relativa e 14 horas de fotofase.

O delineamento experimental foi inteiramente casualizado em esquema fatorial $2 \times 3$ com 30 repetições, sendo cada fêmea considerada uma repetição. Os tratamentos foram os ínstares ninfais de B. tabaci biótipo B nas culturas de couve, tomate e soja. Para analisar o efeito de cada fator, foi realizada análise de variância (teste F) a $5 \%$ de probabilidade, comparando as médias entre os estádios ninfais da praga e as culturas avaliadas.

\subsection{Determinação do número ideal de E. formosa a ser liberado por planta ou ninfa}

Foram realizadas liberações de números variáveis de E. formosa para um número fixo de ninfas de $B$. tabaci biótipo $B$. As ninfas foram obtidas na própria folha da planta hospedeira, através de prévia infestação destas plantas. Estes estudos foram realizados em casa de vegetação, contendo plantas de tomate, soja e couve (plantadas em vasos de $25 \times 22 \mathrm{~cm}$ ), totalizando 20 vasos de cada planta avaliada.

Para se determinar o número ideal de parasitóides, foram realizadas liberações em números variáveis de 40, 80, 160, 320 e 640 fêmeas do parasitóide para um número fixo de 100 ninfas por planta, correspondendo às densidades de 2, 4, 8, 16 e 32 parasitóides por planta, em um total de 5 tratamentos e 20 repetições. Os parasitóides foram coletados com sugador e liberados em canudos plásticos (Figura 1). Estes testes foram conduzidos em casa-de-vegetação sujeita às condições climáticas ambientais.

Birkett et al. (2003) relataram que E. formosa utiliza voláteis provenientes do complexo planta-hospedeiro como pistas olfatórias para a localização do hospedeiro. Dessa forma, foram realizadas liberações em 
cada cultura separadamente para evitar que houvesse interferência no parasitismo e, consequentemente erro na avaliação dos resultados obtidos para cada cultura avaliada.

As plantas ficaram expostas ao parasitismo por um período de um dia, após este período, as folhas contendo ninfas foram levadas ao laboratório para avaliação da porcentagem de ninfas parasitadas. Para evitar que as folhas murchassem e interferissem nos resultados, estas foram recortadas e imediatamente transferidas para placas de plástico (Figura 4), adotando-se o mesmo procedimento utilizado no item 3.3.1. As placas foram mantidas em câmara climatizada regulada a $25 \pm 2^{\circ} \mathrm{C}$ de temperatura, $70 \pm 10 \%$ de umidade relativa e 14 horas de fotofase.

O delineamento experimental foi inteiramente casualizado em esquema fatorial $5 \times 3$ com 20 repetições, sendo cada vaso de planta considerado uma repetição. Os tratamentos foram as densidades de E. formosa nas culturas de couve, tomate e soja. Para analisar o efeito de cada fator, foi realizada análise de variância (teste F) a $5 \%$ de probabilidade, comparando as médias entre as densidades do parasitóide e as culturas avaliadas. 


\section{RESULTADOS E DISCUSSÃO}

\subsection{Avaliação dos aspectos biológicos de Bemisia tabaci biótipo B em diferentes hospedeiros}

Além dos aspectos biológicos da praga, também foram verificadas diferenças em relação aos cultivos de cada cultura avaliada. Dessa forma, verificou-se que a soja e o tomate foram mais propensos ao aparecimento de doenças no período quente e chuvoso, o que prejudicou o desenvolvimento das plantas e, consequentemente, o desenvolvimento de $B$. tabaci biótipo $B$. Entretanto, a couve mostrou-se mais propensa ao ataque de pragas, principalmente pulgões durante o período mais quente do ano.

Através dos resultados obtidos, observou-se que a duração de ovo a adulto de B. tabaci biótipo B em tomate (22,03 dias) foi estatisticamente superior à obtida em soja (21,17 dias) e esta última significativamente superior à observada em couve (19,8 dias) sob as mesmas condições ambientais (Apêndice 1). 
Os resultados obtidos para couve estão de acordo com Simmons (2002) que, avaliando cinco vegetais como hospedeiros de B. tabaci biótipo $B$, verificou que a couve mostrou-se mais atrativa para alimentação e/ou oferece lugares mais fáceis para as ninfas se estabelecerem. No presente trabalho tal afirmação justifica a menor duração no desenvolvimento de ovo a adulto de B. tabaci.

De acordo com Salas \& Mendoza (1995) o período de ovo a adulto de B. tabaci biótipo B em folhas de tomate à $25^{\circ}$ C e $65 \%$ de umidade relativa foi de 22,3 dias, resultado semelhante ao encontrado no presente trabalho (22,03 dias).

O tempo de desenvolvimento de $B$. tabaci biótipo $B$ em folhas de soja (21,17 dias), em condições de laboratório, foi semelhante aos resultados obtidos por Albergaria \& Cividanes (2002). Os autores observaram ciclos biológicos de 70,9 à $15^{\circ} \mathrm{C}$ e 21,8 à $30^{\circ} \mathrm{C}$, com $64 \%$ e $90 \%$ de viabilidade, respectivamente.

O número de ninfas de $B$. tabaci biótipo $B$ em couve foi significativamente superior ao das demais plantas hospedeiras avaliadas, sendo que os resultados obtidos para estas não diferiram entre si pelo teste de Tukey ao nível de $5 \%$ de probabilidade (Apêndice 2).

A couve foi a planta hospedeira avaliada que apresentou menor ciclo total de B. tabaci biótipo B $(19,8 \pm 0,39$ dias $)$, bem como maior número médio de ninfas. Além disso, observou-se que esta hortaliça apresentou sob condições ambientais maior durabilidade e menor incidência de doenças. Portanto, esta hortaliça, dentre as plantas avaliadas, parece ser a planta hospedeira mais adequada ao desenvolvimento de $\mathrm{B}$. tabaci biótipo $\mathrm{B}$. 


\subsection{Avaliação dos aspectos biológicos de Encarsia formosa parasitando pupas de $B$. tabaci biótipo $B$ oriundas de diferentes hospedeiros}

A duração de ovo a adulto de E. formosa em ninfas de primeiro e segundo ínstares em plantas de couve não apresentou diferença significativa, sendo que o mesmo ocorreu em plantas de tomate. Entretanto, na soja a duração deste período em ninfas de primeiro ínstar foi estatisticamente superior a de ninfas de segundo ínstar (Tabela 1).

Quando foram oferecidas ninfas de terceiro e quarto ínstares, o parasitóide apresentou duração maior em ninfas de terceiro ínstar na couve. Em plantas de soja e tomate não foram observadas diferenças significativas para este mesmo período de desenvolvimento nos dois ínstares da praga (Tabela 1).

Nas três culturas avaliadas, E. formosa apresentou períodos de desenvolvimento mais curtos em ninfas de terceiro e quarto ínstares de B. tabaci biótipo B. Dessa forma, o parasitóide parece desenvolver-se melhor nestes estádios ninfais de $B$. tabaci biótipo $B$.

Para ninfas de primeiro ínstar da praga observou-se que em couve e tomateiro o parasitóide apresentou períodos no desenvolvimento de ovo a adulto menores que em soja. Com relação ao desenvolvimento de E. formosa em ninfas de segundo ínstar, não houve diferença significativa para as culturas de couve e tomate que apresentaram duração média de ovo a adulto inferior a da soja (Tabela 1 ).

Em todas as culturas avaliadas não houve diferença significativa no período de desenvolvimento de ovo a adulto de E. formosa em ninfas de terceiro ínstar de B. tabaci biótipo B. Contudo, quando foram oferecidas ninfas de quarto ínstar o parasitóide apresentou um período de desenvolvimento significativamente menor na couve do que nas outras duas plantas hospedeiras, que não apresentaram diferença estatística entre si (Tabela 1). 
Tabela 1. Duração ( $\pm E P$ ) do período de ovo a adulto de E. formosa em ninfas de primeiro, segundo, terceiro e quarto ínstares de $\mathrm{B}$. tabaci biótipo $\mathrm{B}$ em diferentes plantas hospedeiras

\begin{tabular}{cccc}
\hline & \multicolumn{3}{c}{ Planta hospedeira } \\
\cline { 2 - 4 } Estádio & Couve & Soja & Tomate \\
Ninfa I & $16,03 \pm 0,13$ b A & $16,80 \pm 0,32$ a A & $16,30 \pm 0,47$ b A \\
Ninfa II & $15,97 \pm 0,13$ b A & $16,27 \pm 0,39$ a B & $16,03 \pm 0,19$ b A \\
Ninfa III & $15,03 \pm 0,19$ a B & $15,23 \pm 0,36$ a C & $15,10 \pm 0,18$ a B \\
Ninfa IV & $14,10 \pm 0,36$ b C & $15,00 \pm 0,13$ a C & $14,83 \pm 0,28$ a B \\
\hline Médias seguidas por letras distintas maiúscula nas colunas e minúscula nas linhas, \\
diferiram entre si pelo teste de Tukey (P $\leq 0,05) ;$ CV:2,74\%
\end{tabular}

Os resultados obtidos em relação ao período de desenvolvimento de ovo a adulto de E. formosa são difíceis de comparar com outros estudos onde diferentes espécies de mosca-branca e de plantas hospedeiras foram utilizadas. Entretanto, outros pesquisadores geralmente relataram pequenos tempos de desenvolvimento para E. formosa. O tempo de desenvolvimento de E. formosa parasitando quatro ínstares ninfais de T. vaporariorum a $25^{\circ}$ C foi de 15 dias em fumo (Arakawa, 1982), 15 dias em tomate (Burnett, 1949). Antony et al. (2003) relataram que o tempo de desenvolvimento de ovo a adulto de E. transversa sobre $B$. tabaci nas faixas de temperatura de 25 a $30^{\circ} \mathrm{C}$ e de umidade relativa de 70 a $75 \%$ variou de 11,3 a 15,1 dias para as fêmeas e de 12,1 a 14,6 dias para os machos.

Woets \& Van Lenteren (1976) afirmaram que o controle de T. vaporariorum pelo parasitóide E. formosa foi bom em tomate e pimentão, mediano em berinjela, mas pouco eficiente em pepino. Segundo os mesmos autores, pelo menos dois fatores contribuem para estes resultados, tais como a qualidade da planta para o crescimento das fases imaturas da mosca-branca e as características da superfície da planta para a capacidade de busca do parasitóide. Embora o pepino seja um hospedeiro mais 
favorável para o desenvolvimento de T. vaporariorum, suas folhas são menos adequadas para a capacidade de busca do parasitóide devido à venação rentiforme e a presença de tricomas largos. Através dos resultados obtidos em ninfas de $B$. tabaci, observa-se que provavelmente situação semelhante tenha ocorrido em soja, pois embora seja uma planta hospedeira boa para o desenvolvimento da praga, parece não ser muito adequada para E. formosa. Embora as características morfológicas das plantas avaliadas não tenha sido objeto de estudo do presente trabalho, acredita-se que este fator pode ter grande importância para o desenvolvimento do parasitóide.

Soto et al. (2001) observaram que o tempo de desenvolvimento de ovo a adulto de E. formosa foi maior em temperaturas mais baixas $(29,5$ dias a $14,6{ }^{\circ} \mathrm{C}$ ) e foi se reduzindo à medida que a temperatura subia, chegando a 10 dias a $33,5 .{ }^{\circ} \mathrm{C}$. A duração deste período sob o terceiro ínstar ninfal de T. vaporariorum foi ligeramente menor que a correspondente duração sob o quarto ínstar ninfal nas seis temperaturas avaliadas. Este fato poderia estar indicando uma melhor adaptação do parasitóide ao terceiro ínstar da praga. Entretanto, no presente trabalho observou-se que para a soja e o tomate onde não houve diferença significativa na duração do período de ovo a adulto do parasitóide em ninfas de terceiro e quarto ínstares de B. tabaci em condições laboratoriais $\left(25 \pm 10{ }^{\circ} \mathrm{C}\right.$, e na couve a duração do mesmo período em ninfas de quarto ínstar foi significantemente menor que em ninfas de terceiro ínstar.

Os resultados apresentados por Shishehbor \& Brennan (1995) coincidem com os resultados obtidos no presente trabalho. Os autores mostraram que o tempo requerido por $E$. formosa para completar o desenvolvimento de ovo a adulto foi significantemente influenciado pela planta hospedeira onde a mosca-branca se desenvolveu.

Os resultados observados no presente trabalho estão de acordo com Boisclair et al. (1990) que afirmaram que E. formosa apresenta preferência por ovipositar no terceiro e quarto ínstares de seus hospedeiros. 
A utilização de ninfas mais jovens de B. tabaci biótipo B para oviposição por adultos de E. pergandiella levou a um desenvolvimento mais lento dos parasitóides. O mesmo foi verificado com E. formosa no presente trabalho e este fato ocorreu, provavelmente, para permitir o desenvolvimento da mosca-branca hospedeira até o terceiro ínstar garantindo uma fonte adequada de recursos para o desenvolvimento larval, segundo relatado por Liu \& Stansly, (1996).

As estratégias empregadas pelos parasitóides na escolha do ínstar do hospedeiro a ser atacado visam aumento no sucesso reprodutivo, buscando minimizar a mortalidade dos estádios imaturos e maximizar o sucesso de oviposição e utilização do hospedeiro. Estágios mais jovens do hospedeiro são mais abundantes, fáceis de localizar e, algumas vezes, mais indefesos do que ínstares mais velhos. Por outro lado, a oviposição em hospedeiros mais jovens, que têm quantidades pequenas de nutrientes pode levar a uma duração mais longa no desenvolvimento. Assim, com uma duração mais longa o parasitóide estaria exposto por mais tempo aos riscos abióticos e bióticos do meio ambiente, incluindo a atividade de outros inimigos naturais do seu hospedeiro, como também de seus próprios parasitóides (Gerling, 1990).

De acordo com Gould et al. (1975), E. formosa ataca preferencialmente o terceiro ínstar de moscas-brancas e na ausência deste estádio de desenvolvimento, frequentemente oviposita em ninfas mais jovens, causando sua morte e impedindo o estabelecimento da interação hospedeiro/parasita. O momento de introdução do parasitóide em relação à população da praga é, dessa forma, crucial para o controle da praga e os resultados obtidos pelos autores confirmam que um controle satisfatório é obtido através do método de controle biológico clássico.

Enkegaard (1993a) sugeriu que a alimentação do hospedeiro afetou as características biológicas de E. fomosa sobre o "strain" poinsettia de B. tabaci. 


\subsection{Avaliação da eficiência de E. formosa sobre B. tabaci biótipo B}

O parasitismo de E. formosa em ninfas de terceiro e quarto ínstares de B. tabaci biótipo B foi avaliado diariamente, até a morte do parasitóide. A longevidade do parasitóide variou bastante entre as culturas.

Embora tenha sido demonstrado que, em testes sem chance de escolha, diversas espécies de Encarsia ovipositam e desenvolvem-se em todos os ínstares de seus hospedeiros (Lopez-Avila, 1988), segundo Gerling (1990) esta situação ocorre raramente na natureza. Por esta razão e também de acordo com os resultados obtidos no teste anterior, foram utilizados o terceiro e o quarto ínstares ninfais de B. tabaci biótipo B para avaliar a eficiência de E. formosa já que estes mostraram-se mais adequados ao desenvolvimento do parasitóide.

Através dos resultados obtidos para ninfas de terceiro ínstar observase que a soja foi a planta que apresentou menor número médio diário de ninfas parasitadas, diferindo significativamente da couve e do tomate, que por sua vez não apresentaram diferença entre si. Já em ninfas de quarto ínstar houve diferença estatística significativa entre as três culturas avaliadas; na couve observou-se maior número diário de ninfas parasitadas, sendo seguido pelo tomate e pela soja em ordem decrescente (Tabela 2).

Na couve, o número médio diário de ninfas de terceiro ínstar de $B$. tabaci biótipo $B$ parasitadas por $E$. formosa $(8,45 \pm 0,44)$ foi significativamente inferior ao número médio diário de ninfas de quarto ínstar parasitadas $(8,88 \pm 0,52)$. O mesmo resultado foi obtido para a cultura da soja, onde foram parasitadas, em média, 7,51 ninfas de terceiro ínstar e 7,87 de quarto ínstar. Já para o tomate, observou-se que não houve diferença entre os dois estádios ninfais avaliados (Tabela 2). 
Tabela 2. Número médio diário $( \pm E P)$ de ninfas de terceiro e quarto ínstares de B. tabaci biótipo B parasitadas por E. formosa em diferentes plantas hospedeiras

\begin{tabular}{cccc}
\hline & \multicolumn{3}{c}{ Planta hospedeira } \\
\cline { 2 - 4 } Estádio & Couve & Soja & Tomate \\
Ninfa III & $8,45 \pm 0,44$ a B & $7,51 \pm 0,33$ b B & $8,28 \pm 0,22$ a A \\
Ninfa IV & $8,88 \pm 0,52$ a A & $7,87 \pm 0,43$ c A & $8,27 \pm 0,29$ b A \\
\hline
\end{tabular}

Médias seguidas por letras distintas maiúsculas nas colunas e minúsculas nas linhas, diferiram entre si pelo teste de Tukey ( $P \leq 0,05)$; CV:5,19\%

Os resultados obtidos estão compatíveis com os de Enkegaard (1994). O autor observou que um número médio de 0,8 ninfas de $\mathrm{B}$. tabaci por dia podem ser parasitadas por $\mathrm{E}$. formosa à $16^{\circ} \mathrm{C}$, mas esse número sobe para 10,4 ninfas por dia à $28{ }^{\circ} \mathrm{C}$.

No tomate, o número médio de ninfas de terceiro ínstar de $\mathrm{B}$. tabaci biótipo B parasitadas foi significativamente menor do que o obtido para ninfas de quarto ínstar. Entretanto, o número total de ninfas de terceiro e quarto ínstares parasitadas não diferiu estatisticamente. Para as culturas de soja e couve não foi observada diferença entre os estádios ninfais da praga (Tabela 3).

Comparando-se as três culturas avaliadas verifica-se que a couve apresentou número médio total de ninfas parasitadas superior aos valores obtidos para soja e tomate, que por sua vez não apresentaram diferença entre si (Tabela 3). 
Tabela 3. Número médio total ( $\pm E P$ ) de ninfas de terceiro e quarto ínstar de B. tabaci biótipo B parasitadas por E. formosa em diferentes plantas hospedeiras

\begin{tabular}{lccc}
\hline & \multicolumn{3}{c}{ Planta hospedeira } \\
\cline { 2 - 4 } Estádio & Couve & Soja & Tomate \\
Ninfa III & $121,01 \pm 6,27$ a B & $100,98 \pm 8,40$ b B & $105,10 \pm 5,53$ b A \\
Ninfa IV & $129,17 \pm 4,55$ a A & $106,76 \pm 6,05$ b A & $106,12 \pm 5,63$ b A \\
\hline Médias seguidas por letras distintas maiúsculas nas colunas e minúsculas nas linhas, \\
diferiram entre si pelo teste de Tukey (P $\leq 0,05) ; C V: \%$
\end{tabular}

A abundância e a eficiência dos parasitóides estão freqüentemente relacionadas com a dinâmica populacional da mosca-branca que, por sua vez, depende muito da espécie (Headrick et al., 1996), estágio fenológico (Riley \& Ciomperlik, 1997) e genótipo da planta hospedeira (McAuslane et al., 1994). Isto pode explicar as diferenças obtidas no presente trabalho para as culturas avaliadas.

Simmons et al. (2002) demonstraram que a população e a abundância de B. tabaci, assim como a abundância de parasitóides e a taxa de parasitismo podem variar entre as espécies de plantas. Dentre os fatores da planta que podem afetar a eficiência de E. formosa estão a espécie, variedade, características morfológicas como os tricomas (número e tipo) e o número de plantas ao longo do período de cultivo (Hoddle et al., 1998).

O parasitóide não apresentou diferença em relação à longevidade, quando foram oferecidas ninfas de terceiro ou quarto ínstar nas culturas estudadas. Entretanto, verifica-se que para os dois estádios ninfais houve diferença significativa entre as culturas avaliadas. Na couve foi observada a maior longevidade das fêmeas para os dois estádios ninfais de E. formosa (14,33 dias em ninfas de terceiro ínstar e 14,57 em ninfas de quarto ínstar). No tomate foram obtidas as menores longevidades do parasitóide, em média 12,7 dias em ninfas de terceiro ínstar e 12,83 em ninfas de quarto ínstar. $\mathrm{Na}$ 
soja foram encontrados valores intermediários, ou seja, 13,43 e 14,57 dias para ninfas de terceiro e quarto ínstar respectivamente. (Tabela 6).

Tabela 4. Longevidade ( $\pm E P$ ) de E. formosa em couve, soja e tomate

\begin{tabular}{|c|c|c|c|}
\hline \multirow[b]{2}{*}{ Estádio } & \multicolumn{3}{|c|}{ Planta hospedeira } \\
\hline & Couve & Soja & Tomate \\
\hline Ninfa III & $14,33 \pm 0,53$ a $A$ & $13,43 \pm 0,87$ b A & $12,70 \pm 0,51 \mathrm{c} \mathrm{A}$ \\
\hline Ninfa IV & $14,57 \pm 0,52$ a $A$ & $13,57 \pm 0,53 b \mathrm{~b}$ & $12,83 \pm 0,56 \mathrm{c} \mathrm{A}$ \\
\hline
\end{tabular}

A eficiência de procura do parasitóide é influenciada pelas características da superfície da folha da planta e por atributos inatos do parasitóide (Gerling, 1990). O autor relata que folhas rugosas folhas que estão cobertas com poeira e "honeydew" tornam o caminhamento sobre as mesmas muito difícil e, desse modo, reduzem ou até mesmo impedem a movimentação do parasitóide. A probabilidade de se encontrar hospedeiros em folhas de pepino é pequena, devido à baixa velocidade de caminhamento das vespas e ao tempo relativamente longo gasto com a limpeza do corpo

Li et al. (1987) demonstraram que E. formosa caminha mais devagar e requer mais tempo antes de encontrar seu primeiro hospedeiro sobre a folha quando está procurando por hospedeiros em folhas de pepino muito pilosas. A eficiência de parasitismo de E. formosa em folhas de pepino é muito menor em variedades mais pilosas, sendo que a taxa de parasitismo pode reduzir de $72 \%$ em variedades com menor número de pêlos para $58 \%$ (Shishehbor \& Brennan, 1995). 


\subsection{Determinação do número ideal de E. formosa a ser liberado por planta ou pupa}

$\mathrm{Na}$ densidade de dois parasitóides por planta, observou-se que o número de ninfas parasitadas na couve foi superior ao na soja, sendo que esta não diferiu significativamente do tomate. Para a densidade de 4 parasitóides por planta, o número médio de ninfas parasitadas em couve e tomate não apresentaram diferença entre si e foram superiores ao número encontrado em soja. Quando foram liberados oito parasitóides por planta, houve um número de ninfas parasitadas em couve estatisticamente superior aos observados em tomate e soja, e os obtidos nestas não diferiram entre si. Na densidade de doze parasitóides, a soja e o tomate apresentaram número de ninfas parasitadas semelhantes e superiores ao encontrado em couve. Na densidade de dezesseis parasitóides, a couve apresentou número médio de ninfas parasitadas superior ao tomate que, por sua vez, foi superior ao resultado encontrado na soja (Tabela 5 ).

Para a couve observou-se que houve diferença significativa entre todas as densidades do parasitóide avaliadas. O menor número médio de ninfas de B. tabaci biótipo B parasitadas ocorreu na densidade de dois parasitóides por planta. Na densidade de oito parasitóides ocorreu o nível mais alto de parasitismo, sendo que de 100 ninfas oferecidas por planta, foram parasitadas, em média, 59,1 ninfas da praga. Nas densidades de doze e dezesseis parasitóides por planta, parece que ocorreu competição intraespecífica, prejudicando o parasitismo (Tabela 5).

Para o tomate foram encontrados níveis de parasitismo mais baixos que na couve, porém mais elevados que na soja. Na densidade de doze parasitóides por planta ocorreu maior número de ninfas parasitadas que diferiu significativamente das demais densidades avaliadas. Não houve diferença significativa entre as densidades de oito e dezesseis parasitóides por planta. Na densidade de dois parasitóides por planta observou-se o menor número médio de ninfas parasitadas. 
$\mathrm{Na}$ cultura da soja foram observadas diferenças significativas entre todas as densidades avaliadas. Quando foram liberados doze parasitóides por planta, verificou-se um número elevado de ninfas parasitadas, que foi estatisticamente superior aos demais tratamentos. Na densidade de dois parasitóides, foi observado o menor número de ninfas parasitadas. Quando foram liberados dezesseis parasitóides por planta (maior densidade), ocorreu um decréscimo no número de ninfas parasitadas. Embora isto também tenha ocorrido nas outras culturas, na soja foi mais acentuado (Tabela 5).

Segundo Hoddle et al. (1998), observa-se um declínio da eficiência do parasitóide em altas densidades do mesmo que ocorrem devido a diversos fatores, incluindo a alimentação do hospedeiro e níveis moderados de interferência mútua entre parasitóides. Essa afirmação está de acordo com o que ocorreu na soja, tomate e couve na densidade de dezesseis parasitóides por planta.

Tabela 5. Número médio ( $\pm E P$ ) de ninfas de quarto ínstar de $B$. tabaci biótipo B parasitadas por E. formosa em diferentes densidades de E. formosa em couve, tomate e soja

\begin{tabular}{cccc}
\hline & \multicolumn{3}{c}{ Planta hospedeira } \\
\cline { 2 - 4 } Densidade & Couve & Soja & Tomate \\
\cline { 2 - 4 } 2 & $9,00 \pm 1,00$ a E & $6,65 \pm 0,99$ b E & $8,35 \pm 0,82$ ab D \\
4 & $16,30 \pm 1,96$ a D & $11,45 \pm 1,22$ b D & $15,05 \pm 1,30$ a C \\
8 & $59,10 \pm 2,71$ a A & $30,10 \pm 2,64$ c B & $35,10 \pm 2,91$ b B \\
12 & $53,25 \pm 3,35$ b B & $57,65 \pm 3,25$ a A & $59,25 \pm 4,80$ a A \\
16 & $44,40 \pm 2,44$ a C & $27,35 \pm 2,65$ c C & $34,55 \pm 2,60$ b B \\
\hline
\end{tabular}

Médias seguidas por letras distintas maiúsculas nas colunas e minúsculas nas linhas, diferiram entre si pelo teste de Tukey $(P \leq 0,05) ; C V: 10,08 \%$. 
Os níveis de parasitismo podem estar relacionados com o efeito positivo do fluido corporal do hospedeiro e do "honeydew" quando $\mathrm{E}$. formosa alimenta-se de moscas-brancas que se desenvolveram em plantas favoráveis. O fluido corporal da mosca-branca e o honeydew excretado podem ser dependentes da qualidade química da espécie de planta hospedeira.

A planta hospedeira de mosca-branca, segundo Lopez-Avilla (1988) também pode apresentar efeitos significantes sobre os níveis de parasitismo de E. formosa sobre B. tabaci. O autor encontrou números significantemente mais elevados de ninfas parasitadas de mosca-branca em algodão do que em feijão, tomate ou lantana. No presente trabalho foi observado o mesmo para a couve do que em tomate e soja.

Hoddle \& Van Driesche (1996) verificaram que a liberação de 4-7 vespas de E. formosa por planta, não foi satisfatória no controle de B. tabaci biótipo B em bico-de-papagaio. Os autores concluíram que os dois maiores impedimentos para o sucesso do controle biológico de B. tabaci biótipo B são a ausência de inimigo natural efetivo nas empredas que produzem agentes de controle biológico e falta de informação como por exemplo, "qual a estratégia de liberação poderia maximizar o impacto do agente de controle biológico?".

Hoddle et al. (1997a) mostraram que em pequenas casas de vegetação, a liberação de uma vespa (baixa taxa de liberação) de E. formosa "strain" Beltsville e de três vespas (alta taxa de liberação) exerceram forte efeito sobre o crescimento populacional de B. tabaci biótipo $B$ em bico-de-papagaio quando comparadas com casas de vegetação que não receberam o parasitóide. Os mesmos autores verificaram que a liberação semanal de três vespas por planta resultou em densidades finais de B. tabaci biótipo B semelhantes as densidades obtidas em plantas produzidas comercialmente com uso de inseticidas.

Henter et al. (1996) descobriram que uma população de E. formosa criada em B. tabaci por várias gerações parasitou maior número de 
hospedeiros de B. tabaci, mas o condicionamento neste hospedeiro levou esta população a ter um desempenho pior do que quando era condicionada em T. vaporariorum.

O uso de $\mathrm{E}$. formosa pode requerer a integração com outros métodos de controle de pragas. Técnicas que utilizam liberações de $\mathrm{E}$. formosa podem necessitar serem combinadas com outras táticas, como o controle cultural, o uso de outros agentes de controle biológico e a aplicação de inseticidas (Hoddle et al., 1998). Dessa forma, observa-se que estudos envolvendo a integração do parasitóide com outras táticas de controle são necessários. 


\section{CONCLUSÕES}

$\diamond$ O tempo de desenvolvimento de Bemisia tabaci biótipo B é influenciado pela espécie de planta hospedeira.

$\diamond$ O nível de parasitismo e o tempo de desenvolvimento de $\mathrm{E}$. formosa sobre B. tabaci biótipo B é afetado de maneira expressiva pela planta hospedeira.

$\diamond$ A couve é a planta hospedeira mais adequada ao desenvolvimento de E. formosa dentro das plantas avaliadas. 


\section{REFERÊNCIAS BIBLIOGRÁFICAS}

ABDEL FATTAH, M.I.; HENDI, A.; KOLAIB, M.O.; EL SAID, A.; FATTAH, M.I.; ABDEL, SAID A. E.L. Studies on Prospaltella lutea Masi, a primary parasite of the cotton whitefly, Bemisia tabaci (Genn.) in Egypt (Hymenoptera: Aphelinidae). Bulletin de la Societé Entomologique d`Egypte, v.65, p.119-129, 1987.

ALBERGARIA, N.M.S., CIVIDANES, F. J. Exigências térmicas de Bemisia tabaci (Genn.) biótipo B (Hemiptera: Aleyrodidae). Neotropical Entomology, v.31, n.3, p.359-363, 2002.

ANTONY, B.; PALANISWAMI, M.S.; HENNEBERRY, T.J. Encarsia transvena (Hymenoptera: Aphelinidae) development on different Bemisia tabaco Gennadius (Homoptera: Aleyrodidae) instars. Environmental Entomology, v.32, n.3, 584-591, 2003.

ARAKAWA, R. Reproductive capacity and amount of host-feeding of Encarsia formosa Gahan (Hymenoptera: Aphelinidae). Journal of Applied Entomology, v.93, p.175-182, 1982 .

ARRUDA, E.C.F. Nephaspis cocois (Coleóptera: Coccinellidae), novo predador da "mosca-branca" do cajueiro encontrado em Pernambuco. Anais da Universidade Federal de Pernambuco, v.3, p.39-43, 1976. 
BELLOWS JUNIOR, T.S.; PERRING, T.M.; GILL, R.J.; HEADRICK, D.H. Description of a species of Bemisia (Homoptera: Aleyrodidae). Annals of the Entomological Society of America, v.87, n.2, p. 195-206, 1994.

BETHKE, J.A.; PAINE, T.D.; NUESSLY, G.S. Comparative biology, morphometrics and development of two populations of Bemisia tabaci (Homoptera: Aleyrodidae) on cotton and poinsettia. Annals of the Entomological Society of America, v.84, n.4, p.407-411, 1991.

BIN-MOENEN, R.M.; MOUND, L.A. Whiteflies: diversity, biosystematics and evolutionary patterns. In: GERLING, D. (Ed.). Whiteflies: their bionomics pests status and management. Winborne: Intercept, 1990. cap.1, p.1-12.

BIRKETT, M.A.; CHAMBERLAIN, K.; GUERRIERI, E.; PICKETT, J.A.; WADHAMS, L.J.; YASUDA, T. Volatiles from whitefly-infested plants elicit a host-locating response in the parasitoid Encarsia formosa. Journal of Chemical Ecology, v.29, n.7, p.1589-1600, 2003.

BLUA, M.J.; YOSHIDA, H.A.; TOSCANO, N.C. Oviposition preference of two Bemisa species (Homoptera: Aleyrodidae). Environmental Entomology, v.24, n.1, p.88-93, 1995.

BOISCLAIR, J.; BRUEREN, G.J.; VAN LENTEREN, J.C. Can Bemisia tabaci be controlled with Encarsia formosa? SROP/WPRS BULLETIN, v.13, p.32$35,1990$.

BROWN, J.K. Current status of Bemisia tabaci as a plant pest and virus vector in agroecosystems worldwide. FAO Plant Protection Bulletin, v.42, n.1/2, p.3-33, 1994. 
BROWN, J.K.; BIRD, J. Whitefly: transmitted geminiviruses and associated disorders in the Americas and the Caribean Basin. Plant Disease, v.76, n.3, p.220-225, 1992.

BROWN, J.K.; FROHLICH, D.R.; ROSSEL, R.C. The sweetpotato or silverleaf whiteflies: biotypes of Bemisia tabaci or a species complex? Annual Review of Entomology, v.40, p.511-534, 1995.

BRUNT, A.A. Transmission of diseases. In: Cock, M. J. W. (Ed.).Bemisia tabaci: a literature survey on the cotton whitefly with an annotated bibliography. Ascot: CAB International, Institute of Biological Control, 1986. p.43-50.

BURNETT, T. The effect of temperature on an insect host-parasite population. Ecology, v.30, p.113-134, 1949.

BYRNE, D.N.; BELLOWS JUNIOR, T.S. Whitefly biology. Annual Review of Entomology, v.36, p.431-457, 1991.

CABALLERO, R. Chave de campo para imaduros de moscas blancas de Centroamérica (Homoptera: Aleyrodidae). Zamorano: Escuela Agricola Panamericana, 1994. 4p.

CAHILL, M.; BYRNE, F.J.; GORMAN, K.; DENHOLM, I.; DEVONSHIRE, A.L. Pyrethroid and organophosphate resistance in the tobacco whitefly Bemisia tabaci (Homoptera: Aleyrodidae). Bulletin of Entomological Research, v.86, p.343-349, 1995.

COCK, M.J.W. Bemisia tabaci: a literature survey on the cotton whitefly with an annotated bibliography. Ascot: CABI International, Institute of Biological Control, 1986. 121p. 
COSTA, H.S.; BROWN, J.K. Variation in biological characteristics and esterase patterns among populatiuons of Bemisia tabaci and the association of one population with symptom induction. Entomologia Experimentalis et Applicata, v.61, p.211-219, 1991.

COSTA, A.; COSTA, C.L.; SAUER, H.F.G. Surto de mosca branca em culturas do Paraná e São Paulo. Anais da Sociedade Entomológica do Brasil, v.2, n.1, p.20-30, 1973.

COUDRIET, D.L.; PRABHAKER, N.; KISHABA, A.N.; MEYERDIRK, D.E. Variation in developmental rate on different hosts and overwintering of the sweetpotato whitefly, Bemisia tabaci (Homoptera: Aleyrodidae). Environmental Entomology, v.14, p.516-559, 1985.

DE BARRO, P.J. Bemisia tabaci biotype B: a review of its biology, distribution and control. Camberra: CSIRO, 1995. 58p.

DENT, D.R. Integrated pest management. London: Chapman and Hall, 1995. 356p.

De VIS, R.M.J. Biological control of whitefly on greenhouse tomato in Colombia: Encarsia formosa or Amitus fuscipennis? Wageningen, 2001. 165p. Thesis (PhD) - Wageningen University.

DOUTT. R.L. The biology of parasitic Hymenoptera. Annual Review of Entomology, v.4, p.161-182, 1959.

EICHELKRAUT, K.; CARDONA, C. Biologia, cria massal y aspectos ecológicos de la mosca blanca Bemisia tabaci (Gennadius) (Homoptera: Aleyrodidae), como plaga del frijol común. Turrialba, v.39, n.1, p.51$55,1989$. 
ELLSWORTH, P.C. Whitefly management in Arizona cotton-status and needs. In: BELTWIDE COTTON CONFERENCES, Memphis, 1999. Proceedings. Memphis: National Cotton Council, 1999. p.41-44.

ELLSWORTH, P.C.; JONES, J.S. Cotton IPM in Arizona: a decade of research, implementation \& education. In: BELTWIDE COTTON CONFERENCES, Proceedings. Memphis: National Cotton Council, 2001. p.1088-1096.

ELLSWORTH, P.C.; MARTINEZ-CARRILLO, J.L. IPM for Bemisia tabaci: a case study from North America. Crop Protection, v.20, p.853-869, 2001.

ENKEGAARD, A. Encarsia formosa parasitizing the Poinsettia-strain of cotton whitefly, Bemisia tabaci, on Poinsettia: bionomics in relation to temperature. Entomologia Experimentalis et Applicata, v.69, p.251261, 1993a.

ENKEGAARD, A. The poinsettia strain of the cotton whitefly, Bemisia tabaci (Homoptera: Aleyrodidae), biological and demographic parameters on poinsettia (Euphorbia pulcherrima) in relation to temperature. Bulletin of Entomological Research, v.83, p.535-546, 1993b.

ENKEGAARD, A. Temperature dependent functional response of Encarsia formosa parasitizing the Poinsettia-strain of the cotton whitefly, Bemisia tabaci, on Poinsettia. Entomologia Experimentalis et Applicata, v.73, p.19-29, 1994.

FARIA, M.; WRAIGHT, S.P. Biological control of Bemisia tabaci with fungi. Crop Protection, v.20, p.767-778, 2001. 
FERNANDES, O.A. Pragas do melão - Cucumis melo L. In: BRAGA SOBRINHO, R.; CARDOSO, J.E.; FREIRE, F.C.O. (Ed.). Pragas de fruteiras tropicais de importância agroindustrial. Fortaleza: EMBRAPA, CNPAT, 1998. p. 181-189.

FERREIRA, L.T.; AVIDOS, M.F.D. Biotecnologia Ciência \& Desenvolvimento, v 4, p. 22-26, 1996.

FRANÇA, F.H.; VILLAS BOAS, G.L.; BRANCO, M.C. Ocorrência de Bemisia argentifolii Bellows \& Perring (Homoptera: Aleyrodidae) no Distrito Federal. Anais da Sociedade Entomológica do Brasil, v.25, n.2, p.369-372, 1996.

FRANSEN, J.J.; LENTEREN, J. C. van Survival of the parasitoid Encarsia formosa after treatment of parasitized greenhouse whitefly larvae with fungal spores of Aschersonia aleyrodis. Entomologia Experimentalis et Applicata, v.71, p.235-243, 1994

FRANSEN, J.J.; MONTFORT, M.A.J. van Functional response and host preference of Encarsia formosa Gahan (Hymenoptera: Aphelinidae), a parasitoid of greenhouse whitefly Trialeurodes vaporariorum (Westwood) (Homoptera: Aleyrodidae). Journal of Applied Entomology, v.103, p.55-69, 1987.

GAHAN, A.B. Some new parasitic Hymenoptera with notes on several described forms. Proceedings of the United States National Museum, v.65, p.1-23, 1924.

GERLING, D. Biological studies on Encarsia Formosa (Hymenoptera: Aphelinidae). Annals of the Entomological Society of America, v.59, p.142-143, 1966. 
GERLING, D. Observations of the biologies and interrelationships of parasites attacking the greenhouse whitefly, Trialeurodes vaporariorum (West.), in Hawaii. Proceedings of the Hawaiian Entomological Society, v.24, n.2/3, p.217-226, 1983.

GERLING, D. Natural enemies of Bemisia tabaci, biological characteristics and potential as biological control agents: a review. Agriculture, Ecosystems and Environment, v.17, p.1/2, p. 99-110, 1986.

GERLING, D. Natural enemies of whiteflies: Predators and parasitoids. In: GERLING, D. (Ed.)..Whiteflies: their bionomics, pest status and management. Incercept, Andover: 1990. p.147-158.

GERLING, D.; SINAI, P. Buprofezin effects on two parasitoid species of whitefly (Homoptera: Aleyrodidae). Journal of Economic Entomology, v.87, p.842-46, 1994.

GERLING, D.; ALOMAR, O.; ARNÓ, J. Biological control of Bemisia tabaci using predators and parasitoids. Crop Protection, v.20, p.779-799, 2001.

GERLING, D.; MOTRO, U.; HOROWITZ, R. Dynamics of Bemisia tabaci (Gennadius) (Homoptera: Aleyrodidae) attacking cotton in the coastal plain of Israel. Bulletin of Entomological Research, v.70, p.213-219, 1980.

GOOLSBY, J.A.; CIOMPERLIK, M.A.; LEGASPI Jr., B.C.; LEGASPI, J.C.; WENDEL, L.E. Laboratory and field evaluation of exotic parasitoids of Bemisia tabaci (Gennadius) (Biotype "B") (Homoptera: Aleyrodidae) in the Lower Rio Grande Valley of Texas. Biological Control, v.12, p.127135, 1998. 
GOULD, H.J.; PARR, W.J.; WOODVILLE, H.C.; SIMMONDS, S.P. Biological control of glasshouse whitefly (Trialeurodes vaporariorum) on cucumbers. Entomophaga, v.20, n.3, p.285-292, 1975.

HAYAT, M. A revision of the species of Encarsia Foester (Hymenoptera: Aphelinidae) from India and the adjacent countries. Oriental Insects, v.23, p.1-31, 1989.

HEINZ, K.M.; NELSON, J.M. Interspecific interations among natural enemies of Bemisia in an inundative biological control program. Biological Control, v.6, p. 384-93. 1995.

HEINZ, K.M.; PARRELA, M.P. Biological control of Bemisia argentifolii (Homoptera: Aleyrodidae) infesting Euphorbia pulcherrima: evaluations of releases of Encarsia luteola (Hymenoptera: Aphelinidae) and Delphastus pusillus (Coleoptera: Coccinellidae). Environmental Entomology, v.23, n.5, p.1346-1353, 1994a.

HEINZ, K.M.; PARRELA, M.P. Poinsettia (Euphorbia pulcherrima Willd. Ex. Koltz.) cultivar-mediated differences in performance of five natural enemies of Bemisia argentifolii Bellows and Perring, n.sp (Homoptera: Aleyrodidae). Biological Control, v.4, n.4, p.305-318, $1994 \mathrm{~b}$.

HEINZ, K.M.; PARRELA, M.P. Host location and utilization by selected parasitoids of Bemisia argentifolii (Homoptera: Aleyrodidae): Implications for augmentative biological control. Environmental Entomology, v.27, p.773-778, 1998. 
HENNEBERRY, T.J.N.; TOSCANO, N.C.; PERRING, T.M.; FAUST, R.M. (Eds.). Silverleaf Whitefly: National Res., Action, and Technological Transfer Plan, 1997-2001 (Formerly Sweetpotato Whitefly, Strain B): First Annual Review of Second 5-year Plan Held in Charleston, Sourh Carolina, February 3-5, 1998. U.S. Dep. Agric., 1998-2001. 187p. 1998.

HENTER, K.M. Predators and parasitoids as biological control agents of Bemisia in greenhouses. In: GERLING, D., MAYER, R. T. (Ed.) Bemisia: taxonomy, biology, damage, control and management. Andover: Intercept, 1996. p.435-450.

HIGLEY, L.G.; PEDIGO, L.P. Economic thresholds for integrated pest management. University of Nebraska Press, Lincoln: 1997. 589p.

HILJE, L. Metodologias para el estúdio y manejo de moscas blancas y geminivírus. Turriabla: CATIE, 1996. 150p.

HODDLE, M.; VAN DRIESCHE, R. Evaluation of Encarsia formosa (Hymenoptera: Aphelinidae) to control Bemisia argentifolii (Homoptera: Aleyrodidae) on poinsettia (Euphorbia pulcherrima): a lifetable analysis. Florida Entomologist, v.79, n.1, p.1-12, 1996.

HODDLE, M.; VAN DRIESCHE, R.; SANDERSON, J. Biological control of Bemisia argentifolii (Homoptera: Aleyrodidae) on Poinsettia with inundative releases of Encarsia formosa Beltsville strain (Hymenoptera: Aphelinidae): can parasitoid reproduction augment inundative releases? Journal of Economic Entomology, v.90, n.4, p.910-924, 1997a. 
HODDLE, M.; VAN DRIESCHE, R.; SANDERSON, J. Biological control of Bemisia argentifolii (Homoptera: Aleyrodidae) on Poinsettia with inundative releases of Encarsia formosa (Hymenoptera: Aphelinidae): are higher releases rates necessarily better? Biological Control, v.10, p.166-179, 1997b.

HODDLE, M.; VAN DRIESCHE, R.G.; SANDERSON, J. P. Biology and use of the whitefly parasitoid Encarsia formosa. Annual Review of Entomology, v.43, p.645-69, 1998.

HOELMER, K. Whitefly parasitoids: can they control field population of Bemisia? In: GERLING, D., MAYER, R. T. (Ed.). Bemisia: taxonomy, biology, damage and management. Andover: Intercept, 1995. p.451476.

HOROWITZ, A.R.; GERLING, D. Seasonal variation of sex ratio in Bemisia tabaci on cotton in Israel. Environmental Entomology, v.21, n.3, p.556-559, 1992.

HU, J.S., GELMAN, D.B., BLACKBURN, M.B. Growth and development of Encarsia formosa (Hymenoptera: Aphelinidae) in the greenhouse whitefly, Trialeurodes vaporariorum (Homoptera: Aleyrodidae): effect of host age. Archives of Insect Biochemistry and Physiology, v.49, n.3, p.125-126, 2002.

HUNTER, W.B.; POSTON, J.E. Development of a continuous whitefly cell line [(Homoptera: Aleyrodidae); Bemisia tabaci (Gennadius)] for the study of begomovirus. Journal of Invertebrate Pathology, v.77, p.33-36, 2001. 
HUSSEY, N.W.; PARR, W.J.; GOULD, H.J. Observations on the control of Tetranychus urticae Koch on cucumbers by the predatory mite Phytoseiulus riegeli Dosse. Entomologia Experimentalis et Applicata, v.8, p.271-281, 1965.

JAZZAR, C.; HAMMAD, A.F. Efficacy of multiple biological control agents against the sweet potato whitefly Bemisia tabaci (Gennadius) (Homoptera: Aleyrodidae) on tomato. Journal of Applied Entomology, v.128, p.188-194, 2004.

JIANG, N.; XU, R.; VAN LENTEREN, J.C.; VAN ROERMUND, J.W. Temporal and spatial analysis of greenhouse whitefly and its parasitoid Encarsia formosa in two types of greenhouse ecosystems. Journal of Applied Entomology, v.123, p.547-554, 1999.

LACEY, L.A.; MILLAR, L.; KIRK, A.A.; PERRING, T.M. Effect of storage temperature and duration on survival of eggs and nymphs of Bemisia argentifolii (Homoptera: Aleyrodidae) and pupae of the whitefly parasitoid Encarsia formosa (Hymenoptera: Aphelinidae). Annals of the Entomological Society of America, v.92, n.3, p.430-434, 1999.

LI, Z.H.; LAMMES, F.; VAN LENTEREN, J.C.; HUISMAN, P.W.T.; VAN VIANEN, A.; DE PONTI, O.M.B. The parasite-host relationship between Encarsia formosa (Hymenoptera: Aphelinidae) and Trialeurodes vaporariorum (Homoptera: Aleyrodidae). Journal of Applied Entomology, v.104, p.297-304, 1987.

LIMA, L.H.C.; MORETZOHN, M.C.; OLIVEIRA, M.R.V. Survey of Bemisia tabaci (Gennadius) (Hemiptera: Aleyrodidae) biotypes in Brazil using RAPD markers. Genetics and Molecular Biology, v. 23, n.1, p.1-5. 2000. 
LINDQUIST, R.K. Biological control of whiteflies on greenhouse ornamentals. In: Hall, J. A., Ali, A. D., Parrella, M. P. (eds.). CONFERENCE ON INSECT AND DISEASE MANAGEMENT ON ORNAMENTALS. Alexandria, 1988. Proceedings. Alexandria:Society of American Florists,.1988. p.158-162.

LIU, T.X.; STANSLY, P.A. Pupal orientation and emergence of some aphelinidae parasitoids (Hymenoptera: Aphelinidae) of Bemisia argentifolli (Homoptera: Aleyrodidae). Annals of the Entomological Society of America v.89, p.385-90, 1996.

LIU, T.X.; STANSLY, P.A. Life history of Bemisia argentifolii (Homoptera: Aleyrodidae) on Hibiscus rosa-sinensis (Malvaceae). Florida Entomologist, v.81, n.3, p.437-445, 1998.

LOPEZ-AVILLA, A.A comparative study of four species of Encarsia (Hymenoptera: Aphelinidae) as potencial control agents for Bemisia tabaci (Gennadius) (Homoptera: Aleyrodidae). London, 1988. Phd (Thesis). University of London.

LOURENÇÃO, A.L.; NAGAI, H. Surtos populacionais de Bemisia tabaci no Estado de São Paulo. Bragantia, v,53, n.1, p.53-59, 1994.

LOURENÇÃO, A.L.; MIRANDA, M.A.C.; ALVES, S.B. Ocorrência epizoótica de Verticillium lecanii em Bemisia tabaci Biótipo B (Hemiptera: Aleyrodidae) no estado do Maranhão. Neotropical Entomology, v.30, n.1, p.183$185,2001$.

MCAUSLANE, H.J.; JOHNSON, F.A.; KNAUFT, D.A. Population levels and parasitism of Bemisia tabaci (Gennadius) (Homoptera: Aleyrodidae) on peanut cultivars. Environmental Entomology, v.23, p.1203-1210, 1994. 
MANZANO, M.R.; VAN LENTEREN, J.C.; CARDONA, C. Influence of pesticide treatments on the dynamics of whiteflies and associated parasitoids in snap bean fields. BioControl, v.48, p.685-693, 2003.

MARKHAN, P.G.; BEDFORD, I.D.; LIU, S.J.; PINNER, M.S. The transmition of geminiviruses by Bemisia tabaci. Pesticide Science, v.42, p.123-128, 1994.

MEDINA ESPARZA, J.J.; LEON PAUL, R.L. Evaluation of pesticides for the control of whitefly on cotton. In: INIFAP-CIRNO-CEMEXI, Mexicali Valley, 1994. Proceeding. Sacramento: California Department of Food Agriculture, 1994. p.50-55.

MELLO, P.C.T. Mosca branca ameaça produção de hortaliças. Campinas: ASGROW do Brasil Sementes, 1992. 2p.

MINKENBERG, O.P.J.M.; TATAR, M.; ROSENHEIN, J.A. Egg load as a major source of variability in insect foraging and oviposition behaviour. Oikos, v.65, p.134-142, 1986.

MOREIRA, A.N.; HAJI, F.N.P.; DINIZ, R.S.; SANTOS, A.P.; MATTOS, M.A.A.; BARBOSA, F.R.; ALENCAR, J.A. Parasitóides de Bemisia argentifolii em tomateiro e videira no submédio do vale São Francisco. In: ENCONTRO LATINO-AMERICANO E DO CARIBE SOBRE MOSCAS BRANCAS E GEMINIVIRUS, 8., Recife, 1999. p.147.

MURRANT, A.F.; RACCAH, B.; PIRONE, I.P. Transmition by vectors. In: MILNE, R. G. (Ed.). The plant viruses: the filamentous plant viruses. New York: Plenum Press, 1988. p.237-265. 
NARANJO, S.E.; ELLSWORTH, P.C.; HAGLER, J.R. Conservation of natural enemies in cotton: role of insect growth regulators in management of Bemisia tabaci. Biological Control, v.30, p.52-72, 2004.

NAVA-CAMBEROS, U.; RILEY, D.G.; HARRIS, M.K. Temperature and host plant effects on development, survival and fecundity of Bemisia argentifolii (Homoptera: Aleyrodidae). Environmental Entomology, v.30, n.1, p.55-63, 2001.

NECHOLS, J.R.; TAUBER, M.J. Age especific interactions between the greenhouse whitefly and Encarsia formosa: Influence of host on the parasite's oviposition and development. Environmental Entomology, v.6, p. 143-49, 1977.

OLIVEIRA, M.R.V. Controle biológico de Bemisia argentifolii (Bellows \& Perring) com parasitóides. In: CONGRESSO BRASILEIRO DE ENTOMOLOGIA, 16., Encontro Nacional de Fitossanitaristas, 1997. p.9.

OLIVEIRA, M.R.V.; LAUMANN, R.A.; MORAES, F.A.D.; VIEIRA, P.R.G.; CASTRO, A.C. Inimigos naturais coletados na populações de Bemisia tabaci raça $B$ e Trialeurodes vaporariorum (Hemiptera: Aleyrodidae). In: ENCONTRO LATINO-AMERICANO E DO CARIBE SOBRE MOSCAS BRANCAS E GEMINIVIRUS, 7., 1999. p.122

OliVEIRA, M.R.V.; HENNEBERRY, T.J.; ANDERSON, P. History, current status, and collaborative research projects for Bemisia tabaci. Crop Protection, v.20, n.9, p.709-23. 2001.

OSBORNE, L. Temperature-dependent development of greenhouse whitefly and its parasite Encarsia formosa. Environmental Entomology, v.11, p.483-485, 1982. 
PALUMBO, J.C.; HOROWITZ, A.R.; PRABHAKER, N. Insecticidal control and resistance management for Bemisia tabaci. Crop Protection, v.20, p.739-765, 2001.

PARRELLA, M.P.; PAINE, T.D.; BETHKE, J.A.; ROBB, K.L.; HALL, J. Evaluation of Encarsia formosa (Hymenoptera: Aphelinidae) for biological control of sweetpotato whitefly (Homoptera: Aleyrodidae) on poinsettia. Environmental Entomology, v.20, n.2, p. 713-719, 1991.

PATEL, H.M.; JHALA, R.C.; PANDYA, H.V.; PATEL, C.B. Biology of whitefly (Bemisia tabaci) on okra (Hibiscus esculentus). Indian Journal of Agricultural Science, v.62, n.7, p.497-499, 1992.

PAULSON, G.S.; BEARDSLEY, J.W. Whitefly (Hemiptera: Aleyrodidae) egg pedicel insertion into host plant stomata. Annals of the Entomological Society of America, v.78, n.4, p.506-509, 1985.

PERERA, P.A.C.R. Some effects of insecticide deposit patterns on the parasitism of Trialeurodes vaporariorum by Encarsia formosa. Annals of Applied Biology, v.101, p.239-244, 1982.

PERRING, T.M.; COOPER, A.D.; RODRIGUEZ, R.J.; FARRAR, C.A.; BELLOWS Jr., T.S. Identification of a whitefly species by genomic and behavioral studies. Science, v.259, p.74-78, 1993a

PERRING, T.M.; FARRAR, C.A.; BELLOWS, T.S; COOPER, A.D.; RODRIGUEZ, R.J. Evidence for a new species of withefly: UCR findings and applications. California Agriculture, v.47, n.1, p.7-8, 1993b. 
POLASZEK, A.; EVANS, G.A.; BENNET, F.D. Encarsia parasitoids of Bemisia tabaci (Hymenoptera: Aphelinidae; Homoptera: Aleyrodidae): a preliminary guide to identification. Bulletin of Entomological Research, v.82, p.375-392, 1992.

PRABHAKER, N.; TOSCANO,N.C.; PERRING, T.M.; NUESLSLEY, G.; KIDO, K. ; YOUNGMAN, R.R. Resistance monitoring of the sweetpotato whitefly (Homoptera: Aleyrodidae) in the Imperial Valley of California. Journal of Economic Entomology, v.85, n.4, p.1063-1068, 1992.

RAO, N.V.; REDDY, A.S.; RAO, K.T. Natural enemies of cotton whitefly, Bemisia tabaci Genn. in relation to host population and weather factors. Journal of Biological Control, v.3, p.10-12, 1989.

RAVENSBER, G.W.J. A quality control test for Encarsia formosa (Hymenoptera: Aphelinidae) and the results of a ten year period. IOBC/WPRS Bulletin, v.5, p.80-89, 1991.

RILEY, D.G.; CIOMPERLIK, M.A. Regional population dynamics of whitefly (Homoptera: Aleyrodidae) and associated parasitoids (Hymenoptera: Aphelinidae). Environmental Entomology, v.26, p.1049-1055, 1997.

RILEY, D.G.; PALUMBO, J.C. Action threshold for Bemisia argentifolii (Homoptera: Aleyrodidae) in Cantaloupe. Journal of Economic Entomology, v.88, n.6, p.1733-38, 1995.

ROMBACH, M.C.; GILLESPIE, A.T. Entomogenous hypomycetes for insect and mite control on greenhouse crops. Biocontrol News and Information, v.9, p.7-18, 1988. 
RUMEI, X. A systems model for host plant-whitefly-Encarsia relationships to investigate optimal biological strategies. IOBC/WPRS Bulletin, v.10, p.183-187, 1987.

RUMEI, X. Improvements of the plant-pest-parasitoid (PPP) model and its application on whitefly-Encarsia population dynamics under different release methods. Journal of Applied Entomology, v.112, p.274-287, 1991.

RUSSELL, L.M. Synonyms of Bemisia tabaci (Gennadius) (Homoptera: Aleyrodidae). Bulletin of Brooklyn Entomological Society, v.52, p.122-123, 1957.

SALAS, J.; MENDOZA, O. Biology of sweetpotato whitefly (Homoptera: Aleyrodidae) on tomato. Florida Entomologist, v.78, p.154-60, 1995.

SAMPSON, A.C.; KING, V.J. Macrolophus caliginosus, field establishment and pest control effect in protected tomatoes. IOBC/WPRS Bulletin, v.16, p.145-148, 1996.

SANDERSON, J.P.; FERRENTINO, G.W. Performance of Encarsia formosa shipments from commercial insectaries. IOBC/WPRS Bulletin, v.16, 1992, p.145-148.

SCHUSTER, D.J.; FUNDERBURK, J.E.; STANSLY, P.A. Selected IPM programs: tomato. In: ROSEN, D., BENNETT, F. D., CAPINERA, J. L. (Ed.). Pest management in the subtropicals: integrated pest management: a Florida perspective. Andover: Intercept, 1996, p.387412. 
SCHUSTER, D.J.; STANSLY, P.A., POLSTON, J.E. Expressions of plant damage by Bemisia. In: GERLING, D., MAYER, R. T. (Ed.).Bemisia: taxonomy, biology, damage and management. Andover: Intercept, p.153-165, 1995.

SCHUSTER, D.J.; MUELLER, T.F.; KRING, J.B.; PRICE, J.F. Relationship of the sweetpotato whitefly with a silverleaf disorder of squash. Hortscience, v.25, p.1618-1620, 1990.

SCOPES, N.E.A.; PICKFORD, R. Mass production of natural enemies. In: HUSSEY, N. W., SCOPES, N. (Ed.). Biological pest control: the glasshouse experience. Ithaca: Cornell University Press, 1985, p.197209.

SHISHEHBOR, P.; BRENNAN, P.A. Parasitism of Trialeurodes ricini by Encarsia formosa: level of parasitism, development time and mortality on different host plantas. Entomophaga, v.40, n.3/4, p.299-305, 1995.

SHISHEHBOR, P.; BRENNAN, P.A. Functional response of Encarsia formosa Gahan parasitizing castor whitefly Trialeurodes ricini Misra (Homoptera: Aleyrodidae). Journal of Applied Entomology, v.120, p.297-299, 1996.

SILVEIRA, C.A. O novo ritmo da proteção: mosca-branca. In: SEMANA INTERNACIONAL DE FRUTICULTURA E AGROINDÚSTRIA, 7. Fortaleza, 2000. Fortaleza: Sociedade de Fruticultura Brasileira 2000. p.1-4.

SIMMONS, A. Nymphal survival and movement of crawlers of Bemisia argentifolii (Homoptera: Aleyrodidae) on leaf surfaces of selected vegetables. Environmental Entomology, v.28, n.2, p.212-216,1999. 
SIMMONS, A.M. Settling of crawlers of Bemisia tabaci (Homoptera: Aleyrodidae) on five vegetable hosts. Annals of the Entomological Society of America, v.95, n.4, p.466-468, 2002.

SIMMONS, A.M.; McCUTCHEON, G.S. Daily foraging incidence of Encarsia pergandiella (Hymenoptera: Aphelinidae) on cowpea. Journal of Entomology Science, v.36, p.218-221, 2001.

SIMMONS, A.M.; ABD-RABOU, S.; MCCUTCHEON, G. Incidence of parasitoids and parasitism of Bemisia tabaci (Homoptera: Aleyrodidae) in numerous crops. Environmental Entomology, v.31, n.6, p.10311036, 2002.

SOTO, A.; NORERO, A.; APABLAZA, J.; ESTAY, Y.P. Requerimientos térmicos para el desarrollo de Encarsia formosa (Hymenoptera: Aphelinidae) criado em Trialeurodes vaporariorum (Hemiptera: Aleyrodidae). Ciencia e Investigacion Agraria, v.28, n.2, p.103-106, 2001.

SOUZA, A.P.; VENDRAMIM, J.D. Efeito de extratos aquosos de meliáceas sobre Bemisia tabaci biótipo B em tomateiro. Bragantia, v.59, n.1, p.173-179, 2000.

SPEYER, E.R. Biological control of the greenhouse whitefly. Nature, v.76, p.1009-10010, 1930.

STENSETH, C. Temperaturens betydning for utviklingean av snyltevepsen Encarsia formosa. Gartneryrket, v.65, p.136-139, 1975.

STENSETH, C.; AASE, I. Use of the parasite Encarsia formosa (Hym.: Aphelinidae) as a part of pest management on cucumbers. Entomophaga, v.28, n,1, p.17-26. 1983. 
SUMMERS, C.G.; NEWTON JÚNIOR, A.S.; ESTRADA, D. Intraplant and interplant movement of Bemisia argentifolii (Homoptera: Aleyrodidae) crawlers. Environmental Entomology, v.25, n.6, p.1360-1364, 1996.

SÜTTERLIN, S.; VAN LENTEREN, J.C. Influence of hairness of Gerbera jamensonii on the searching efficiency of the parasitoid Encarsia formosa. Biological Control, n.9, p.157-65. 1997.

TOSCANO, N.C.; CASTLE, S.J.; HENNEBERRY, T.J.; PRABHAKER, N. Persistent silverleaf whitefly exploits desert crop systems. California Agriculture, v.52, n.1, p.29-33, 1998.

TSAI, J.H.; WANG, K. Development and reproduction of Bemisia argentifolii (Homoptera: Aleyrodidae) on five host plants. Environmental Entomology, v.25, n.4, p.810-816, 1996.

VALLE, G.E. Resistência de genótipos de soja a Bemisia tabaci biótipo $B$. Campinas, 2001. 80p. Dissertação (Mestrado). Instituto Agronômico de Campinas.

VAN LENTEREN, J.C. Quality control of natural enemies: Hope or illusion? IOBC/OILB Bulletin, v.5, p.1-14, 1991.

VAN LENTEREN, J.C. Designing and implementing quality control of beneficial insects: Towards more reliable biological pest control. IOBC/OILB Bulletin, v.7, p.67-72, 1993.

VAN LENTEREN, J.C. Integrated pest management in protected crops. In: DENT, D. R. (Ed.). Integrated pest management: principles and systems development. London: Chapman \& Hall, 1995. p. 311-343. 
VAN LENTEREN, J.C.; BRASCH, K. Variation in acceptance and parasitization of Bemisia tabaci by Encarsia formosa. International Organization for Biological Control West Paleartic Regional Section Bulletin, v.17, p.96-103, 1994.

VAN LENTEREN, J.C.; HULPAS-JORDAAN, P.M. Encarsia formosa can control greenhouse whitefly at low temperature regimes. IOBC/WPRS Bull. v.10, p.87-91.1987.

VAN LENTEREN, J.C.; WOETS, J. Biological and integrated control in greenhouses. Annual Review of Entomology, v.33, p.239-269, 1988.

VAN LENTEREN, J.C.; NELL, H.W.; SEVENSTER-van der LELIE, L.A.S. The parasite-host relationship between Encarsia formosa (Hymenoptera: Aphelinidae) and Trialeurodes vaporariorum (Homoptera: Aleyrodidae). IV - Oviposition behaviour of the parasite, with aspects of host selection, host discrimination and host feeding. Zeitschrift fur Angewandte Entomologie, v.89, p.442-454, 1980.

VAN LENTEREN, J.C.; VAN ROERMUND, H.J.W.; SUTTERLIN, S. Biological control of greenhouse whitefly (Trialeurodes vaporariorum) with the parasitoid Encarsia formosa: How dows it work? Biological Control, v.6, p.1-10, 1996.

VAN LENTEREN, J.C.; DROST, Y.C.; VAN ROERMUND, H.J.W.; POSTHUMADOODEMAN, C.J.A.M. Aphelinidae parasitoids as sustainable biological control agents in greenhouses. Journal of Applied Entomology, v.121, p.473-485, 1997. 
VAN LENTEREN, J.C.; POSTHUMA-DOODEMAN, C.J.A.M.; ROSKAM, M.; WESSELS, G. Quality control of Encarsia formosa: Flight tests. IOBC/WPRS Bulletin, v.19, p.87-89, 1996.

VAN ROERMUND, H.J.W. Understanding biological control of greenhouse whitefly with the parasitoid Encarsia formosa. Wageningen, 199. 243p. Thesis (PhD). Wageningen Agriculture University.

VAN ROERMUND, H.J.W.; VAN LENTEREN, J.C. Foraging behavior of the whitefly parasitoid Encarsia formosa on tomato leaflets. Entomologia Experimentalis et Applicata, v.76, p.313-324, 1995.

VAN VEIRE, M. Yellow sticky cards as an alternative tool for the control of the greenhouse whitefly and leaf miners in greenhouse tomatoes. IOBC/WPRS Bulletin, v.8, p.51-54, 1985.

VAN VEIRE, M.; DEGHEELE, D. Toxicity of the fungal pathogen Paecilomyces fumosoroseus strain Apopka 97 to the greenhouse whitefly Trialeurodes vaporariorum, and the parasite Encarsia formosa, and first results of a control experiment in glasshouse tomatoes. IOBC/WPRS Bulletin, v.19, p.191-194, 1996.

VAZQUEZ, L.L. Mosca blanca-geminivírus en el Caribe: estado actual y perspectivas. In: TALLER LATINOAMERICANO $Y$ DEL CARIBE SOBRE MOSCAS-BLANCAS Y GEMINIVÍRUS, 7., 1999, Recife, PE, Brazil. Recife: 1999. p.45-58.

VASQUEZ, L.L.; JIMÉNEZ, R.; IGLESIA, M.de la; MATEO, A.; BORGES, M. Plantas hospederas de Bemisa tabaci (Homoptera: Aleyrodidae) en Cuba. Revista de Biologia Tropical, v.45, n.1, p.143-148, 1997. 
VET, L.E.M.; VAN LENTEREN, J.C..; WOETS, J. The parasite-host relationship between Encarsia formosa Gahan (Hymenoptera: Aphelenidae) and Trialeurodes vaporariorum (Westwood) (Homoptera: Aleyrodidae). IX. A review of the biological control of the greenhouse whitefly with suggestions for future research. Journal of Applied Entomology, v.90, p.26-51, 1980.

VIGGIANI, G.; MAZZONE, P. Contributi alla conoscenza morfo-biologica delle especie del complexo Encarsia Foerster - Prospaltella Ashmead (Hym. Aphelinidae). Bollettino del Laboratorio di Entomologia Agraria "Filippo Silvestre", v.36, p.42-50, 1979.

VIGGIANI, G. Le specie italiane Del genere Encarsia Foerster (Hymenoptera: Aphelinidae). Bollettino del Laboratorio di Entomologia Agraria "Filippo Silvestri", v.44, p.121-179, 1987.

VILAS BÔAS, G.L.; FRANÇA, F.H.; ÁVILA, A.C.; BEZERRA, I.C. Manejo integrado da mosca-branca Bemisia argentifolii. Brasília: Embrapa, CNP Hortaliças, 1997. 12p. (Embrapa. CNP Hortaliças. Circular Técnica, 9).

VILAS BÔAS, G.L.; FRANÇA, F.H.; ÁVILA, A.C.; BEZERRA, I.C. Avaliação da preferência de Bemisia argentifolii por diferentes espécies de plantas. Horticultura Basileira. V.19, n.2, p.130-134, 2001.

WAGNER, T.L. Temperature-dependent development, mortality, and adult size of sweetpotato whitefly biotype B (Homoptera: Aleyrodidae) on cotton. Environmental Entomology, v.24, n.5, p.1179-1188, 1995. 
WANG, K.; TSAI, J.H. Temperature effect on development and reproduction of silverleaf whitefly (Homoptera: Aleyrodidae). Annals of the Entomological Society of America, v.89, n.3, p.375-384, 1996.

WARDLOW, L.R.; LUDLAM, A.B.; BRADLEY, L.F. Pesticide resistance in glasshouse whitefly (Trialeurodes vaporariorum Westw.). Pesticide Science, v.7, p.320-324, 1976.

WEBB, R.E.; SMITH, F.F. Greenhouse whitefly control of an integrated regimen based on adult trapping and nymphal parasitism. IOBC/WPRS Bulletin, v.3, p.235-246, 1980.

WOETS, J.; LENTEREN, J.C.van. The parasite-host relationship between Encarsia formosa (Hymenoptera: Aphelinidae) and Trialeurodes vaporariorum (Homoptera: Aleyrodidae). VI. The influence of the host plant on the greenhouse whitefly and its parasite Encarsia Formosa. West Paleartic Regional Section Bulletin, v.4, p.151-164, 1976.

WOOL, D.; CALVERT, L.; CONSTANTINO, L.M.; BELLOTTI, A.C.; GERLING, D. Diferentiation of Bemisia tabaci (Genn.) (Homoptera: Aleyrodidae) populations in Colombia. Journal of Applied Entomology, v.117, p.122-134, 1994.

YANO, E. Population responses of Encarsia formosa to the greenhouse whitefly and their role in population dynamics of whitefly- E. formosa system. IOBC/WPRS Bulletin, v.10, p.193-197, 1987.

YEE, W.L.; TOSCANO, N.C. Ovipositional preference and development of Bemisia argentifolii (Homoptera: Aleyrodidae) in relation to alfafa. Journal of Economic Entomology, v.89, n.4, p.870-876, 1996. 
YOKOMI, R.K.; HOELMER, K.A.; OSBORNE, L.S. Relationships between the sweetpotato whitefly and the squash silverleaf disorder. Phytopathology, v.80, p.895-900, 1990.

YOSHIMOTO, C.M. The insects and arachnids of Canadá. Ottawa, Biosystematics Research Institute, 1984. 149p.

ZCHORI-FEIN, E.; ROUSH, R.T.; HUNTER, M.S. Male production induced by antibiotic treatment in Encarsia formosa (Hymenoptera: Aphelinidae) an asexual species. Experimentia, v.48, p.102-105, 1992.

ZUCCHI, R. A.; SILVEIRA NETO, S.; NAKANO, O. Guia de identificação de pragas agrícolas. Piracicaba: FEALQ. 1993. 139p. 
Apêndice 1. Tempo de desenvolvimento de ovo a adulto ( $\pm E P$ ) de $B$. tabaci biótipo $\mathrm{B}$ em diferentes plantas hospedeiras

\begin{tabular}{cccc}
\hline & \multicolumn{3}{c}{ Planta hospedeira } \\
\hline Estádio & Couve & Soja & Tomate \\
Ovo a adulto & $19,8 \pm 0,39 \mathrm{c}$ & $21,17 \pm 0,29 \mathrm{~b}$ & $22,03 \pm 0,32 \mathrm{a}$
\end{tabular}

Médias seguidas por letras distintas nas linhas, diferiram entre si pelo teste de Tukey $(P \leq 0,05) ; C V: 2,50 \%$ 
Apêndice 2. Número médio ( $\pm E P$ ) de ninfas de $B$. tabaci biótipo $B$ em diferentes plantas hospedeiras

\begin{tabular}{cccc}
\hline \multicolumn{3}{c}{ Planta hospedeira } \\
\hline Estádio & Couve & Soja & Tomate \\
Ninfas & $90,17 \pm 19,06$ a & $72,0 \pm 10,27 \mathrm{~b}$ & $63,93 \pm 8,22 \mathrm{~b}$ \\
\hline édias seguidas & por letras distintas & nas linhas, diferiram entre si pelo teste de \\
key $(\mathrm{P} \leq 0,05) ; \mathrm{CV}: 23,57 \%$
\end{tabular}
Tukey $(P \leq 0,05) ; C V: 23,57 \%$ 